\title{
10
}

\section{In Defense of Non-Sentential Assertion}

\author{
Robert J. Stainton
}

In what follows, I introduce a pragmatics-oriented approach to non-sentential speech, and defend it against two recent attacks. Among other things, I will rehearse and elaborate a defense against the idea that much, or even all, of such speech is actually syntactically elliptical — and hence should be treated semantically, rather than pragmatically. The chapter is structured as follows. In Section 1 I introduce the phenomenon, contrast semantic versus pragmatic approaches to it, and explain some of what hinges on which approach is taken. In Section 2 I present Jason Stanley's objections to the pragmatics-oriented approach, and his counterproposal that all truth-conditional effects of context on what is asserted can be traced to elements of underlying structure. In Section 3 I canvass numerous varieties of ellipsis. The focus in Section 3 will be on what kind of "ellipsis" is required if the pragmatics-oriented approach is actually to be rejected rather than being recast in other terms. In Section 4 I respond to

Work on this chapter was supported by a grant from the Social Sciences and Humanities Research Council of Canada, held jointly by myself and Ray Elugardo of the University of Oklahoma, and covering the years 1999-2002. I would like here to express my great debt to Professor Elugardo for many useful discussions, and of numerous issues, surrounding non-sentential speech. I'm also grateful, in particular, for his help on the present chapter. Thanks also to Ash Asudeh, Alex Barber, Ellen Barton, Emma Borg, Lenny Clapp, Steven Davis, Corinne Iten, Dave Matheson, Jason Merchant, Ljiljana Progovac, Aryn Pyke, Zoltán Szabó, and Catherine Wearing for very useful comments on a previous draft. This chapter is dedicated to my daughters, Moonisah and Saima- both because they speak sub-sententially all the time, and because they unknowingly encourage me to maintain a healthy perspective on debates about semantics versus pragmatics. 


\section{4 / Robert J. Stainton}

Stanley, and show that the two known varieties of ellipsis which would turn the trick for the semantics-oriented approach are not empirically plausible when applied to the cases in question. In further defense of this conclusion, in Section 5 I present a family of syntactic arguments, from Peter Ludlow and others, in favor of ellipsis (and a concomitant semantics-based approach), and I give replies to these latter arguments. In Section 6, the final section, I return explicitly to issues of the semantics-pragmatics boundary, and I draw some larger lessons about what sub-sentential speech does and does not entailincluding in particular what it does not entail vis-à-vis the distinctiveness of linguistic communication, and the viability of truth-conditional semantics.

\section{Introduction: Non-Sentences and the Semantics-Pragmatics Boundary}

Let me begin with the phenomenon to be explained, whether semantically or pragmatically. It seems that agents can produce ordinary words and phrases (more precisely, lexically headed phrases, though I'll abbreviate to the shorter term in what follows) and thereby perform speech acts. In particular, what will be the focus of this chapter, they apparently can make assertions while speaking sub-sententially. Spelling this out a little, speakers seemingly can and do utter maximal projections of lexical items: noun phrases, verb phrases, prepositional phrases, etc. (This includes, of course, cases where the phrase consists of a single word.) And the things they utter can be of semantic type $\left\langle_{e}\right\rangle_{,},\left\langle_{e, t}\right\rangle$, $<<e, t>, t>$ and so on. Hence speakers need not, and do not, only utter inflectional phrases (i.e. maximal projections of inflectional elements like tense and subject agreement), which projections are more commonly known as sentences in the syntactic sense, when performing speech acts. Nor do they only utter things of type $<_{t}>$, also known as sentences in the semantic sense, when performing genuine speech acts. ${ }^{1}$

Here is an attested case in point. Meera was spooning out strawberry jam onto her toast, and produced (or, more safely, appeared to produce) the phrase 'Chunks of strawberries'. Anita nodded, and (seemingly) added 'Rob's mom'. It appears that Meera asserted something like This jam contains chunks of strawberries, while Anita asserted something like Rob's mom made it. In both cases, they appear to have made true statements while using something sub-sentential. Or again, to take a case I have discussed elsewhere (Stainton 1997a: 61), it seems that

\footnotetext{
1 I discuss various senses of 'sentence' in Stainton (2000).
} 
someone could hold up a letter and say 'From Spain', thereby claiming, about the displayed letter, that it comes from Spain.

Now, it's crucial that in the above description of the phenomenon there was regular reference to what seemed or appeared to be the case. It's important to speak in this manner because there are two quite different ways to react to such appearances. One may take the appearances at face value, and conclude that speakers really do utter plain old words or phrases, and thereby perform speech acts. Or one may treat the appearances as illusory — saying that where a speech act really is performed, the thing produced isn't really a word or phrase after all. Of particular interest here, these two ways of reacting assign different weights to semantics and pragmatics. The pragmatics-oriented approach takes the appearances at face value, and concludes that pragmatics does rather more, even in literal conversation, than is sometimes allowed - in particular, pragmatics provides the missing real-world object (or property or whatever) which joins with the linguistic content of the word or phrase to yield what is asserted, stated, or claimed. The semantics-oriented approach denies the appearances, and maintains that syntax, and with it semantics, are doing more than what meets the eye.

Let me spell out the two competing approaches a bit, before turning briefly to the question of why it matters which one is correct. Starting with the pragmaticsoriented approach, the view would be roughly this: Speakers really do utter unembedded lexical projections (including single words), with both the syntax and semantics of such items. Applied to the above examples, the view would be that the speaker tokened, and the hearer recovered, the very things which occur embedded in (1) through (3) - though on the occasion in question they appeared unembedded in any larger linguistic structure:

(1) [Chunks of strawberries] are expensive.

(2) [Rob's mom] lives in Toronto.

(3) I flew here [from Spain].

According to the pragmatic story, in order to treat the speaker as genuinely communicating, in a relevant way, the hearer must look for a proposition which the speaker meant to convey. After all, Meera could not have intended to convey only what the ordinary phrase 'chunks of strawberries' literally encodes in English, since what it encodes is not a proposition; nor could the speaker of 'From Spain' have meant the property $\lambda x[$ from Spain $(x)]$, which is more or less what that prepositional phrase expresses. The hearer, therefore, must not only recover the semantic content of the word or phrase, but must also draw on linguistic and non-linguistic information, from context, to supply the missing property (as in the former example) or the missing object (as in the latter 


\section{6 / Robert J. Stainton}

example). (I stress: on the pragmatics-oriented view, what is intended by the speaker and recovered by the hearer is a missing property or object, not a missing predicate or referring term. This contrast will loom large in what follows.) The sub-sentential speaker intends the hearer to do all of this; and said speaker's intentions play a key role in determining both the content and the illocutionary force of the utterance. Thus it is that the utterance can be an assertion of a complete proposition, even though the word or phrase uttered and recovered does not itself encode a proposition, even relative to a context. In short, on this approach, pragmatics fills the major gap between (a) linguistically encoded content and $(b)$ what is conveyed by the speaker.

There are, in the literature, two competing views on how pragmatics fills this gap. Barton (1989 and elsewhere) maintains that there are pragmatic submodules that do the job. Specifically, though speaking roughly, she postulates(i) a sub-module of linguistic context, that operates exclusively on the sub-sentence uttered plus prior explicit discourse, and (ii) a sub-module of conversational context, that takes the output of the first sub-module as input, and uses non-linguistic context (provided by vision, olfaction, background knowledge, short-term memory, etc.) to derive what the speaker meant to convey. For Barton, both modules perform non-deductive, context-sensitive inferences, which - as typically happens with inductive and abductive inferences — do not necessarily and determinately yield a single result. Still, in general, the first sub-module is more automatic and rule-driven than the second - applying, for example, to discourse sequences (e.g. non-sentential answers to wh-questions). The alternative approach, pursued in Stainton (1993, 1994, and elsewhere), is to agree with Barton that the "filling in" occurs via non-deductive inference rather than "decoding", but to deny that there are pragmatics modules at workappealing instead to central system processes, inferential processes not specific to language, to bridge the gap. ${ }^{2}$ (In contrast, as both Barton and Stainton agree, the language system proper, which is a distinct module for both of them, is conceived as performing purely formal derivations, rather than inferences — which derivations are context-free and determinately yield one or more meanings for the string.) I put aside this in-house dispute here, defending the pragmatics-oriented

\footnotetext{
2 The pragmatics-oriented theorist obviously owes a concrete story of how the bridging occurs: a general outline is not enough. Within the "pragmatics module" camp, see Barton (1990) for a carefully worked out attempt. Within the non-modular camp, see Stainton (1993, 1994) and (at least with respect to fairly simple cases in which a predicate is used and an object is visually salient) Elugardo and Stainton (2003). This latter paper also addresses in much greater detail the issues surrounding integration of information from non-linguistic modes during speech comprehension.
} 
approach construed broadly to include both sub-varieties. What is worth stressing is that, on either approach, it is pragmatics and not syntax-semantics per se which also triggers the hearer's attempt to fill the gap. Not only is the search carried out by a pragmatic process, it is begun by one. This is clear because sometimes words and phrases are used to do something other than communicate a proposition: e.g. in labels, book titles, lists, and so on. (Or so it seems.) Hence merely producing a word or phrase in isolation cannot trigger the quest for a proposition-meant. Instead, producing them in a situation in which only a proposition would be pragmatically appropriate is key.

Importantly, the pragmatics-oriented theorist need not treat the proposition communicated as merely a variety of implicature, or anything of the sort. For example, it seems perfectly plausible that someone who utters 'From Spain', while demonstrating a letter, does not merely implicate the proposition, about the displayed letter, to the effect that it is from Spain; she actually asserts this. Thus, the pragmatics-oriented approach can be committed to non-sentential assertions, not just to non-sentential (but fully propositional) communication. ${ }^{3}$

\footnotetext{
${ }^{3}$ For further discussion of non-sentential speech, including extended discussion of its philosophical implications, the reader is directed to Elugardo and Stainton (2004) and to my earlier papers. Here is a brief synopsis of the latter. In Stainton (1997a) I argue, on the basis of non-sentential assertions, that Michael Dummett's (1973) analysis of assertion-according to which, put roughly, an assertion just is the utterance of a declarative sentence under conventionally specified circumstances - cannot be correct. I therefore propose, instead, that the utterer's complex mental state plays a central role in determining that something is an assertion. (A useful and insightful discussion of my critique can be found in Kenyon 1999.) In Stainton (1997b) I point out that to arrive at utterance-meaning from expression-meaning it is not sufficient to disambiguate and assign reference to indexicals. This is a point I will try to drive home in the present chapter. I also argue that, assuming the existence of genuine syntactic ellipsis, it is not necessary, for finding literal utterancemeaning, to discover precisely what expression was uttered. In particular, the hearer doesn't need to know whether the speaker uttered an (elliptical) sentence or just a lexical projection to find what was literally asserted - since the correct interpretation could be the same either way. In Stainton (1998a), reprinted in Davis and Gillon (forthcoming), I contend that the meaning of quantifier phrases should not be given by a metalinguistic rule which describes the meaning of potential whole sentences containing such phrases; I urge instead that, quantifier phrases being usable without any sentence frame whatever, the appropriate semantics would have them denoting generalized quantifiers. In Stainton (1998b), I draw a similar lesson for definite descriptions. In Stainton (2000) I show that the familiar doctrines (a) that "only sentences can be used in isolation", and (b) that "only sentences have meaning in isolation", each have three quite distinct readings, two of which readings are interesting (but not well supported), and the third of which is well supported (but not interesting). Finally, in Elugardo and Stainton (2001), Ray Elugardo and I argue, this time on the basis of the ability to make less than sentential arguments, that there are things other than natural language expressions which have logical forms; and not only that, but said things have their logical forms non-derivatively. For an overview article, see Stainton (2004).
} 


\section{8 / Robert J. Stainton}

It is, of course, often quite tricky to sort out what is asserted from what is merely conveyed. We have intuitions about such things, including especially intuitions about whether an utterance is lie-prone, and hence truly assertoric. But it's hard to give necessary and sufficient conditions on "assertion-hood" which honor all of those intuitions. (And it's also sometimes hard to know how seriously to take the intuitions, independently of practical reasons for distinguishing assertion from mere communication - a point I return to later in the chapter.) This is equally true when sub-sentential speech is at issue. But a natural first pass at a generalization about sub-sentence cases — which, for the most part, captures the intuitions correctly - goes like this. Sub-sentential expressions are sub-propositional - in the sense that, to arrive at a proposition, they must be supplied with an argument, or they must modify a certain kind of content, or what-have-you. Thus the expression 'From Spain' doesn't express a proposition, and neither does 'Chunks of strawberries', etc. Leaving details aside, what is asserted when a sub-sentence is used communicatively is that proposition which results from minimally saturating the content of the bare phrase actually uttered. Non-asserted content is inferentially arrived at content which goes beyond the minimal proposition, such that the enrichment is forced not by the sub-propositional nature of the thing uttered, but solely by considerations of the conversational inadequacies of the propositional result of "saturating". An example may help to illustrate this way of contrasting what is asserted and what is merely conveyed, as applied to sub-sentence use. Consider the following dialogue from The Presidential Transcripts, as reported in Barton (1989: 8):

(4) President Nixon: Somebody is after him [Maurice Stans] about Vesco. I first read the story briefly in the Post. I read, naturally, the first page and turned to the Times to read it. The Times had in the second paragraph that [Vesco's] money had been returned, but the Post didn't have it.

\footnotetext{
${ }^{4}$ I should stress that I take no stand here on the larger issue of whether there is, in every case, only one "minimal proposition" so arrived at. Nor do I intend to claim that the first proposition arrived at is, in every case, the only one literally asserted. For one thing, arguably in sentential speech the "minimal proposition" sometimes isn't asserted, or isn't the only one asserted. Thus what I say here is intended to be consistent with an utterance of 'I've had breakfast' being a literal statement to the effect that "I've had breakfast already today", even if the latter isn't the first proposition accessed. (See Bach (1994b) for discussion of such "expansion" cases.) Being a "first pass", I also leave aside the difficult detail of how 'breakfast'-type cases might arise with sub-sentential speech. Presumably, a Sperber and Wilson (1986) style story applies in this case, just as it does in sentential speech: a propositional form which is a "development" of the minimal one is asserted; a propositional form which is produced by something more robust than Sperber and Wilson's "development" is implicated only. That said, laying out a detailed proposal would take me too far a field. (See Stainton 1994 for a bit more.)
} 
John Dean: That is correct.

H. R. Haldeman: The Post didn't have it until after you continued to the back section. It is the (adjective omitted) thing I ever saw.

John Dean: Typical.

Here, Dean non-sententially asserts, of the salient event described by Nixon and Haldeman, that it was typical. This is asserted, on the proposed account, rather than merely being implicated, because the content of 'Typical', being an adjective that must apply to some thing or event, would otherwise remain subpropositional. That content becomes fully propositional, however, as soon as the contextually salient event - i.e. so publishing the Vesco story — is conjoined with this content. So this, and only this, is asserted. Now suppose, as might well have been the case, that Dean in so speaking also conveyed the information that he disapproves of the fact that such events are typical for the Post. On the proposed account, this extra content would not be asserted; it would merely be implicated. The reason is that this content goes well beyond the minimal proposition one gets by finding an appropriate content for 'Typical' to combine with. Crucially, what makes the former filling-in-to-arrive-at-what-is-asserted pragmatic is that the saturation is not a matter of linguistic derivation, but is instead a matter of all-purpose inference triggered by the pragmatic unfitness of the sub-propositional content - where, moreover, the inference is based on both linguistic context and other kinds of knowledge. ${ }^{5}$ (Indeed, if Elugardo and Stainton 2003 are on the right track, it couldn't be linguistic derivation, because what is arrived at is not an item of natural language syntax - it is a content, rather than a syntactic form, that is sought; and it is sought by the agent as a whole.)

Thus ends this brief overview of the pragmatics-oriented approach. Let's turn to the more semantics-heavy approach. It will hold that, in cases of apparent sub-sentential assertion, the expression type which the speaker actually tokened does not simply encode an object, property, or what-have-you. Despite the sound heard, the expression type uttered will be said to encode a proposition - or, more exactly, the type will be said to encode a propositional character. How exactly this is done will be one focus of what follows. But, put roughly for

\footnotetext{
5 What the search process does resemble is finding an appropriate referent for a demonstrative: both kinds of search are triggered (albeit in quite different ways) by the "incomplete", sub-propositional, semantics of the expression uttered, and both involve context-sensitive, non-deductive inference. However, as will emerge below, the pragmatics-oriented theorist denies, on empirical grounds, that there are "covert" demonstratives being filled in, in sub-sentential speech. Thus, on the pragmaticsoriented view, sub-sentential speech cannot be reduced to reference assignment to "slots".
} 


\section{0 / Robert J. Stainton}

now, there are two possibilities. First, it might be that there is ordinary syntactic material present at some level, such that this material is elided, i.e. "deleted" somehow, so that it goes unpronounced. Second, it might be that the expression produced contains special indexical items of a sort which are never pronounced. Notice that on both versions, the sound produced maps onto a more complex syntactic structure than what the sound pattern initially suggests, with that syntactic structure then mapping onto semantic content in a normal way. Thus, on both stories, there is a somewhat unorthodox, non-obvious, mapping from sound pattern to syntax, but a perfectly normal mapping from syntax to semantics. ${ }^{6}$ I take this to be the heart of syntactic ellipsis. (See Stainton 2004 for discussion.) How does this help the semantics-oriented approach? Well, on either syntactic ellipsis story, returning to Meera's utterance, the syntactic item that Meera used, and that her interlocutor recovered - the type that is - will be claimed to have the same context-invariant semantics as the sentence type 'This has chunks of strawberries'. (Or something like that.) Thus the syntactic structure uttered is of semantic type $\langle t\rangle$ after all, despite the sound produced. Context is required to get a particular true or false proposition - there are still gaps to be filled, and they must be filled by pragmatics - but this is the usual state of affairs. In particular, on the semantics-oriented approach, only something quite familiar needs to be done: in the first variant, pragmatics helps determine which expression type was uttered (the sound produced, taken alone, leaves the nature of the unpronounced material underdetermined), and in both variants pragmatics helps supply the non-linguistic input for the propositional character encoded by the expression type uttered, so that this character can output a proposition-meant. But, says the proponent of the semanticsoriented approach, this is no different than when a speaker produces an ambiguous expression, and/or one containing a context-sensitive item. ${ }^{7}$

${ }^{6}$ Actually, there is still another way to save the semantics-oriented approach. One might propose that the sound is mapped to the syntactic structure that one would expect, but that this structure has a special context-invariant meaning when it occurs unembedded. This would be what I've elsewhere called "semantic ellipsis". The parallel here is with "one-word sentences", and special uses of words like 'Out' as said by a baseball umpire, or 'Attention' as said by a sergeant. I mostly ignore this option here. Detailed discussion of this idea may be found in Stainton (1995) and, under the rubric of "shorthand", in (Elugardo and Stainton 2004b).

7 In fact, there are at least two other theories of syntactic ellipsis familiar from the literature. Dalrymple et al. (1991) treat ellipsis as trying to find not an unpronounced syntactic structure, but something more like a semantic content having certain properties. (Similar ideas may be found in Crouch 1995, and also in Schachter 1977.) I discuss this kind of view in Section 3, pointing out that it does not provide any solace to semantics-oriented approaches to sub-sentential speech. See also n. 14. A different account is due to Williams (1977), who posits an empty element, $\Delta$, that works like 
Having introduced the phenomenon and the pragmatics versus semanticsoriented approaches to it, I'd like to briefly canvass here why it matters who is right. (I'll return to the issue of implications at length in the final section of the chapter.) Most obviously, the (apparent) phenomenon of sub-sentential speech raises a subtle question about where to draw the semantics-pragmatics boundary in such cases: Is the job of pragmatics in these cases merely to disambiguate and/or find appropriate contents for (unpronounced) indexicals, with the semantics providing a "slot" (where "slots" include indexicals, tense markers, demonstratives, covert variables, etc.) that needs to be filled? Or does pragmatics do rather more, and semantics rather less?

The debate about where to draw the boundary in these cases has become important for a narrower reason as well. In the last twenty-five years or so, numerous theorists have challenged the (purportedly) Gricean view that pragmatics plays only two roles:

(5) The "Gricean picture" of the two roles for pragmatics

(a) Disambiguating and finding items to fill linguistically provided "slots", thereby contributing to what is asserted, stated, or said;

(b) Determining non-literal content which goes beyond "what is said" (e.g. determining conversational implicatures).

Carston (1988), Récanati (1989), Searle (1978, 1980), Sperber and Wilson (1986), and Travis $(1985,1996,1997)$ have all argued, contra the (purportedly) Gricean line, that there are pragmatic determinants of what is literally stated, asserted, or said which cannot be traced to elements of linguistic structure. ${ }^{9}$ This has become known as the thesis of pragmatic determinants of what is said. (This thesis is closely related to the idea

an anaphor: $\Delta$ gets co-indexed with prior appropriate linguistic material which was actually pronounced, and takes over its content from that overt material. This contrasts with the second view to be addressed in the body of the text, which will have ellipsis being a matter of a context-sensitive item deictically picking out a non-linguistic object or property. (Roughly speaking, the postulated empty element that I will discuss in this chapter is more like 'that' and PRO, while Williams's $\Delta$ is closer to 'himself' and NP-trace.) It would take me too far afield to treat Williams's view here. Put in a nutshell, however, my view is that in so far as Williams's view is different from Dalrymple et al., when read as a proposal for (apparent) sub-sentential speech, it is subject to the same objections that will be raised against deletion-type views.

${ }^{8}$ Equally, but now with respect to the illocutionary force of the speech act, rather than its propositional content: can speaker's intentions (pragmatics) determine that something is an assertion, or must this be done by the "linguistic conventions" (semantics)? For discussion, see Stainton (1997a).

${ }^{9}$ In my view, Kent Bach belongs in this list as well. This may surprise some readers, because Bach (1994a, b, and elsewhere) has repeatedly argued that there are no pragmatic determinants of what is said. However, what Bach means by 'what is said' is something rather narrower than what his (supposed) opponents have in mind. Whereas the authors listed here mean something illocutionary and of 


\section{2 / Robert J. Stainton}

that there exist what Perry 1986: 138 calls 'unarticulated constituents': a constituent of the propositional content of the speech act for which there is no corresponding constituent in the expression uttered.) Now, as first noted in Stainton (1997b), subsentential speech provides another example of pragmatic determinants of what is stated, asserted, or claimed - at least if the pragmatics-oriented approach sketched above is the right one. To see this, consider again the 'From Spain' example. On the pragmatics-oriented approach, this phrase is not ambiguous, and contains no "slots" needing to be filled. What was uttered was simply the ordinary phrase 'From Spain', which is a prepositional phrase of semantic type $\left.<_{e, t}\right\rangle$. Thus the result of process (5a) will remain something of semantic type $\left.<_{e, t}\right\rangle$, since disambiguation and slot-filling will contribute nothing. It is the fact that this content is not pragmatically fit - it being non-propositional - that triggers further "saturation". And yet, the case was claimed to be one of assertion: the person holding the envelope literally stated, of the letter, that it was from Spain. The speaker did not merely conversationally implicate a proposition, while stating nothing propositional at allshe made a literal claim. Thus the content asserted is of semantic type $<t>$, not $\langle e, t\rangle$. In which case, pragmatics is playing a role in determining the truth conditions of what is stated, asserted, or said that goes well beyond what the (purportedly) Gricean view allows.

The issue of where to draw the semantics-pragmatics boundary in such cases also ties in with a topic that has been central to cognitive science of late. That topic is informational integration, specifically how information that comes from linguistic processing gets integrated with information that comes from other modes - memory, vision, inference, etc. The role of semantics and pragmatics in sub-sentential speech provides a nice case study of just this debate: the semantics-oriented approach has the integration happening via the encoding of non-linguistic kinds of information into a natural language format, with that non-linguistic material making it into communicated content either by the reconstruction of bits of descriptively contentful syntax (variant one of "syntactic

necessity propositional when they speak of 'what is said', i.e. what is asserted, stated, or claimed, Bach seems to mean, by definition, the merely locutionary result of disambiguation and slot-filling. Putting the terminological confusion aside, Bach would emphatically agree that pragmatics plays a role in determining what is asserted, stated, or claimed. Indeed, his implic- $i$-tures (in contrast to implic- $a$-tures) help bridge the "gap" between what disambiguation and slot-filling yield (his notion of 'what is said') and what is asserted/stated/claimed. But Bach's (1994b) implicitures are patently pragmatically determined. Speaking of Bach, it's also worth noting that he denies that Grice meant anything illocutionary by the phrase 'what is said'. If this is right, then maybe even Grice himself allowed that what is asserted is pragmatically determined. To avoid exegetical complications, I usually speak of the "purportedly Gricean view" of the determinants of what is asserted, stated, or claimed. 
ellipsis"), or by becoming the non-linguistic referent of linguistically provided "slots" (ordinary ones like 'this' in variant one, special pronunciation-free ones in variant two). A consequence of the pragmatics-oriented approach, in contrast, seems to be that integration of information from other sources during speech understanding can happen without additional natural language encoding of the information coming from other sources. Put another way, the idea is that environmental and other information need not be translated into descriptive natural language, or even be made the referent of natural language items, in order to be understood by a hearer as part of speech content. Instead, putting things very roughly, the output of the language faculty is presumably combined with other kinds of information in a neutral code of some sort, say Mentalese. (This debate leads quickly to even larger questions about the relationship between thought and talk. But those issues must be left for another day.)

In a series of papers I have repeatedly defended the pragmatics-oriented approach to (apparently) non-sentential assertions. I have also defended the two consequences of that approach noted above: the idea that integration in such cases occurs in something other than natural language, and the idea that there are pragmatic determinants of what is asserted, stated, or said. The latter conclusion has been explicitly rejected by Jason Stanley in his admirably bold paper 'Context and Logical Form' (Stanley 2000). He there argues that all truth-conditional effects of context trace to elements in the (possibly covert) structure of the item spoken. The former position is threatened as well by novel arguments presented by Peter Ludlow and others, drawing on work in theoretical syntax. As noted at the outset, my aim in this chapter is to rebut these arguments, thereby defending the pragmatics-oriented approach. By way of reply, I will shortly introduce numerous "varieties of ellipsis". Having narrowed down the kind of ellipsis which must be in play, if the pragmatics-oriented view is to be genuinely rejected, I will (among other things) rebut Stanley and Ludlow's arguments for ellipsis. I will end by discussing in greater detail the implications of the pragmatics-oriented approach here defended. The first step, however, is to explain Stanley's critiques.

\section{Stanley's Challenge to the Pragmatics-Oriented Approach}

As sketched briefly above, one way to resist the genuineness of sub-sentential assertion is by appealing to syntactic ellipsis. Another way is to argue that speakers aren't really performing speech acts in so speaking. Finally, one could say that 


\section{4 / Robert J. Stainton}

it's "semantic ellipsis": crudely, that speakers are using "one-word sentences" (and "one-phrase sentences"), with the syntax of words or phrases, but the semantics of complete sentences. I have argued (Stainton 1997b) that syntactic ellipsis, whether in the reconstruction variant or the empty element variant, cannot account adequately for the appearances. I have also argued (Stainton 1995, 1997a) that "semantic ellipsis" cannot turn the trick either. Having also rebutted the claim that what is being done is something less than assertion, this seemed enough to show that the phenomenon ought to be treated pragmatically, rather than semantically. Jason Stanley pointed out, correctly, that this is not enough. Stanley's fundamental insight is that, even granting that none of these strategies taken alone can work, a "divide and conquer" strategy might allow one to combine these various gambits, thereby rejecting the genuineness of non-sentential assertion after all. He writes:

The persuasiveness of Stainton's arguments is due in part to the tacit assumption that all alleged examples of non-sentential assertion must be treated by the same general strategy. However, there is no reason to accept this assumption. I do not believe that there is a uniform phenomenon underlying all apparent examples of non-sentential assertion. (Stanley 2000: 403)

Stanley then goes on to argue that some cases might be syntactic ellipsis, for all I have said; and that some cases might not be assertions; and that some cases might be "semantically elliptical" (he calls it "shorthand") in some sense. I will address these one at a time.

It is exceedingly tempting, upon first reflecting on the use of things like 'Chunks of strawberries' and 'From Spain' to perform speech acts, to suppose that these are actually not less-than-sentential. Instead, goes this tempting idea, these and related cases involve the utterance of elliptical sentences. One natural comparison is with what B says in examples like (6)-(9):

(6) A: Will Juan move to Madrid?

B: Yes, he will.

(7) A: Juan already lives in Madrid.

B: No, he doesn't.

(8) A: Who lives in Madrid?

B: Juan doesn't.

(9) A: Juan will soon move to Madrid.

B: I wonder why.

It's very natural to say, about these four examples, that in each case B uttered a complete sentence, containing, for instance, not only a subject and an auxiliary, 
but also a main verb, a complement, and so on - this despite the fact that what B pronounced does not sound complete. A standard view is that the expression produced is a whole sentence nevertheless, at one level of representation, but that material which usually receives some pronunciation is deleted, or otherwise omitted, in these cases. (As explained above, there is another way to treat these cases, namely with empty elements that are never pronounced. I will address that option in Section 5.) Specifically, one might say that at some level the sentences uttered by B were:

(10) Yes, he will [move to Madrid].

(11) No, he doesn't [already live in Madrid].

(12) Juan [doesn't live in Madrid].

(13) I wonder why [Juan will soon move to Madrid].

Let's agree that B's utterances in examples (6)-(9) are paradigm cases of syntactic ellipsis. The aim, then, is to explain away apparent examples of nonsentential speech by assimilating them to the broad phenomenon illustrated by (6)-(9).

As I say, this is a very tempting thought. However, as Nancy Yanofsky (1978) and Ellen Barton (1989, 1990) first stressed, this assimilation seems unlikely to succeed, because there are several key differences between the paradigm cases of ellipsis in (6)-(9) and (apparent) examples of less-thansentential speech, of the sort exemplified by uttering 'From Spain' in isolation. One such difference is this: whereas B's utterances demand a linguistic context, 'From Spain' can occur discourse initially. Thus consider an utterance of 'No, he doesn't' in discourse initial position. It would be exceedingly awkward. Similarly for 'I wonder why'. So, one reason for rejecting the "tempting idea" is this: whereas non-sentence cases can occur discourse initially, familiar cases of syntactic ellipsis cannot. Hence the former cannot be assimilated to the latter.

I have frequently used this appeal to occurrence in discourse initial position. In particular, I've used it to derail attempts to reduce apparently sub-sentential speech to fully sentential, but elliptical, speech. The objection Stanley makes against me here is that, while some cases of non-sentential speech genuinely are discourse initial, and hence are not plausibly treated as genuine syntactic ellipsis, many other examples are not truly discourse initial. More precisely, Stanley charges that the notion of "discourse initial" that I invoke is overly restrictive. Once the notion is broadened, so that no gestures or other means of making sentences salient are allowed, says Stanley, it turns out that many speech acts which appear to be discourse initial really are not. Here is his own example 


\section{6 / Robert J. Stainton}

(I have altered the numbering):

Now consider the following context. Suppose Bill walks into a room in which a woman in the corner is attracting an undue amount of attention. Turning quizzically to John, he arches his eyebrow and gestures towards the woman. John replies:

(S5) a world famous topologist. (Stanley 2000: 404)

What Stanley says about this example is that John's utterance of (S5) should not count as discourse initial in any interesting sense. Rather, the quizzical glance, the arched eyebrow, the pointing gesture, and all the rest raise a question ${ }^{10}$ to salience, namely: 'Who is she?' (Stanley 2000: 406). So the utterance isn't discourse initial after all. Given that this "implicit prior discourse" exists, elliptical expressions are licensed - and it is precisely this implicit prior discourse that permits the use of (S5). Hence, he concludes, this is simply the use of an elliptical sentence with prior discourse. Stanley goes on to consider a use of (S5) with absolutely no background context, that is, with no linguistic items either explicitly spoken or otherwise made salient. This is a "discourse initial situation" in a broader sense. He suggests that 'A world famous topologist' cannot be felicitously used in such a context. Hence, it is fallacious to conclude that 'A world famous topologist' is truly non-sentential, on the grounds that it "can occur discourse initially" - because, in fact, it can do no such thing. (The same critique would presumably apply, mutatis mutandis, to my 'From Spain' example, and to many others.)

As noted, Stanley conjectures that by combining several strategies, one can explain away all apparent cases of sub-sentential speech. By dodging the "discourse initial" test, Stanley seemingly extends the compass of the syntactic ellipsis strategy, as just seen. The next sub-category into which he will put some cases are utterances which are truly sub-sentential, but which are not really assertoric. It certainly seems that speakers really can use a plain old word or phrase in discourse initial position - in the broad sense in which no linguistic material has been made previously salient at all, either by being explicitly spoken, or by pointing gestures, eyebrow arching, or what-have-you. Stanley considers in particular the example of a thirsty man who staggers up to a street vendor and utters 'Water'. He grants that this utterance occurs discourse initially in the broader sense. Hence, he concedes, it cannot plausibly be treated

\footnotetext{
${ }^{10}$ In Elugardo and Stainton (2004b) we point out that what Stanley really needs is for an interrogative to be salient. It isn't sufficient, to avoid pragmatic determinants of what is asserted, for a question (i.e. issue or topic) to be salient. Rather, what is required is a uniquely salient linguistic expression. We then argue that in very many cases no unique interrogative will be salient.
} 
as a syntactically elliptical sentence. However, Stanley says, one should not conclude on this basis that there are genuine non-sentential assertions, because "I doubt that the thirsty man has made a linguistic speech act" (2000: 407). He gives two reasons for this. The first is that the utterance of 'Water', in the example in question, was not performed with a determinate force - in particular, it is not at all obvious that the thirsty man uttered 'Water' with determinate assertoric force. It could with equal right (i.e. not much right) be treated as a request, or a command. The second reason for denying that a genuine speech act was performed is that, according to Stanley, genuine linguistic acts must have determinate propositional contents. But, plausibly, the thirsty man's utterance of 'Water' cannot be assigned such a determinate content. Stanley concludes: "The available facts simply do not determine a determinate propositional content for the alleged assertion. And when a communicative act lacks a determinate content, it is not a linguistic speech act" (2000: 408). Now, if many of the cases of alleged non-sentential assertion can be placed in this category (i.e. genuinely non-sentential, but not genuinely assertoric), then further progress can be made towards his desired (immediate) conclusion, namely that all alleged cases can be explained away by assigning them to the appropriate sub-category.

The final category into which the alleged cases are to be placed are utterances of apparent words or phrases which (a) really do have a determinate force and a determinate propositional content but, $(b)$ occur discourse initially in the broader sense, with no gestures or what-have-you, and hence are not elliptical. To illustrate this sub-category, imagine someone utters 'Nice dress' to a woman passing by in the street. Here, it is agreed on both sides, an assertion has been made, about the dress, to the effect that it is a nice dress. There is no indeterminacy of force: this is clearly not a question, and it is equally clearly not an order. Instead, the speaker is in every sense making a statement. And yet there is neither prior spoken discourse, nor implicit linguistic expressions made salient by gestures and such. What Stanley says about this example is that "it is intuitively plausible to suppose, in this case, that the speaker simply intended her utterance to be shorthand for 'that is a nice dress' " (2000: 409). ${ }^{11}$

Stanley summarizes his overall objection as follows:

Each and every alleged example of non-sentential assertion can be classified in one of the three ways I have described [i.e. as elliptical, not genuinely linguistic, or "shorthand"]. The illusion that each strategy is unsatisfactory stems from the tacit assumption that, to

${ }^{11}$ For detailed discussion of the "shorthand" gambit, see Elugardo and Stainton (2004b). 


\section{8 / Robert J. Stainton}

be satisfactory, a strategy must work for each case of an alleged non-sentential assertion. The assumption presupposes that the "phenomenon" of non-sentential assertion constitutes a natural kind. Once this presupposition has been abandoned, it is far less clear that there are any actual everyday examples of non-sentential assertion. (Stanley 2000: 409)

\section{Varieties of Ellipsis}

In Section 1 I noted two possible consequences of taking a pragmatics-oriented approach to the phenomenon at hand. The first consequence was that non-sentential assertions provided genuine-indeed glaring-examples of pragmatic determinants of what is asserted, stated, or said. The second consequence was that the integration of linguistically derived information with other sorts, in speech comprehension, might not happen in the medium of natural language. Specifically, it might not simply be a matter either of recovering extra syntactic material, or of simply filling in a referent for a linguistically provided "slot". Rather, on the pragmatics story, a representation from vision, olfaction, or what-have-you, without "translation", gets combined with a representation (but not of type $<_{t}>$ ) coming from the language faculty. (For detailed, albeit uncomfortably speculative, discussion, see Elugardo and Stainton 2003.)

Stanley wants to say that the first consequence does not hold, because $(a)$ in many purported cases, nothing is asserted and $(b)$ in the remaining purported cases, what is asserted is not pragmatically determined (in the sense required), because the case is either one of "shorthand" or of syntactic ellipsis, hence really of "slot-filling" after all (albeit of an unpronounced "slot"). This strategy would also mean that integration of non-linguistic content, in understanding supposedly sub-sentential speech, actually does happen by somehow getting nonlinguistic things represented by items of natural language.

Before addressing Stanley's arguments head on, it will be important to distinguish several varieties of ellipsis. ${ }^{12}$ In particular, if his line of response is to

${ }^{12}$ In what follows I speak of "varieties of ellipsis" and the like. This is actually loose talk, in the sense that not all of the things described are sub-varieties of one single phenomenon. Sometimes what are presented are conflicting theories about one single phenomenon, not different varieties of that thing. And sometimes what are presented are not varieties of one natural kind, but are rather quite different phenomena that have nevertheless had the label "ellipsis" applied to them. I believe this loose talk is harmless in this context. 
avoid the two consequences just noted, the Constraint below must hold:

(14) The Not-Just-Recasting Constraint. If the speech act is syntactically elliptical, then it's not a case of pragmatics determining what is asserted, and it's not a case of integration occurring outside the medium of spoken language.

In fact, this Constraint - which makes ellipsis a way of rejecting the pragmaticsoriented approach, rather than a way of recasting it in other terms - is nontrivial. Whether it is met depends enormously on which variety of ellipsis is at play, and on how one takes each variety of ellipsis to work.

Let me first introduce and put aside a "loose" version of ellipsis that would not satisfy the Constraint. Some philosophers, as well as some ordinary folk, speak of "ellipsis" whenever context (linguistic or otherwise) has to play an important role in filling in what the speaker said - whenever, put colloquially, the utterer "spoke elliptically" by leaving something implicit or unspoken. Sub-sentential speech clearly is "elliptical" in this very loose sense, since context is undoubtedly helping to determine a proposition which was not explicitly articulated. However, saying this is not to reject the pragmatics-oriented approach; it is, rather, to put a different label on things, while granting the general soundness of the pragmatics-oriented approach. This loose sense of 'ellipsis' would include, for example, Sellars's (1954) notion, ${ }^{13}$ and what Neale (2000) calls "the explicit approach to quantifier incompleteness". On that kind of approach, the expression type which the speaker appeared to utter is precisely what she did utter. At best what one can say, taking Neale's "explicit" approach, is that the speaker could have used something more complete, while performing the same speech act. But, patently, if S produced $u$, though S could have produced $u^{\prime}$, it's

${ }^{13}$ Sellars writes, about uttering 'Seven is' in a dialogue, that "utterances of 'Seven is' are as such not complete and are only made complete by the context in which they are uttered ... Let us call this type of ambiguity ellipsis and say that in ellipsis the context completes the utterance and enables it to say something which it otherwise would not, different contexts enabling it to say different things" (1954: 200). Sellars goes on to chastise Strawson for the latter's failure to distinguish completion of this "elliptical" variety from the kind one finds when sentences contain what I have called "slots" (i.e. indexicals, tense markers, etc.). Sellars equally distinguishes his "ellipsis" variety of ambiguity from the more familiar kind in which one has to figure out what expression has really been uttered (e.g. which of the different words pronounced/baenk/was used). Clearly, then, Sellars does not think of "ellipsis" either as the presence of "hidden variables" that need to be filled in by context, or as a matter of figuring out what completed expression was "really" uttered. It seems clear, to the contrary, that his notion of "ellipsis" involves the context functioning directly to change the statement made, without doing so via elements of syntax. Thus ellipsis in his sense, far from rejecting pragmatic determinants of what is asserted, stated, or said, is fully committed to their existence. 


\section{0 / Robert J. Stainton}

nevertheless the case that $S$ did produce $u$. Applied to a sub-sentence example, notice that if the speaker really did utter 'From Spain' in making an assertion then-even if context somehow completes her act, indeed even if she could have uttered some full sentence instead, so that the speech act counts as "elliptical" in the sense at work in the explicit approach — what she actually did was to make an assertion using a non-sentence. In what follows, then, I will never use 'ellipsis' in this loose sense.

Another move that is no real help to the semantics-oriented story is to use 'ellipsis' in some avowedly technical sense, all the while stressing that the kind of ellipsis at play, whatever it is, must be very unlike the familiar forms that occur within sentences. Until a detailed positive account is given, this amounts, once again, to simply adopting a comforting label. I think this move is especially problematic, in the present context, because in speaking this way it remains wholly unclear whether the Constraint would be satisfied or not, since it gets left open what "syntactic ellipsis" amounts to. Yet one rests content dismissing the phenomenon as "just ellipsis" anyway. It is for good reason, then, that when Stanley, Ludlow, and others endorse syntactic ellipsis and thereby reject the pragmatics-oriented approach to (apparently) sub-sentential speech, I read them not only as having some quite technical sense of 'ellipsis' in mind, but also as intending to assimilate, at least in broad strokes, (apparently) sub-sentential speech to VP-ellipsis, sluicing or some other kind of ellipsis familiar from sentence grammar. Where my opponents resist being so read, one must conclude that they have yet to offer a version of syntactic ellipsis that truly satisfies the Constraint.

I have already introduced two "varieties of ellipsis" that won't help the semantics-oriented theorist. I now want to introduce a third. One might think that sub-sentential talk is like VP ellipsis (and such) in that, in both kinds of cases, some non-linguistic stuff, or some semantic content, is supplied contextually but without accompanying hidden syntactic structure. If that is one's view of so-called "syntactic ellipsis" generally — and, very roughly, it is the view of Crouch (1995), Dalrymple (2004), Dalrymple et al. (1991), and Schachter (1977), among othersthen the Constraint is simply not met. ${ }^{14}$ Indeed, if all "syntactic ellipsis" works like

\footnotetext{
${ }_{14}$ For example, on the Higher-Order Unification approach of Dalrymple and her colleagues, resolution of ellipsis is a matter of trying to solve an equation that relates the meaning of the ellipsis antecedent to the meaning of the elliptical expression. Thus, in 'Samir likes Kirit. Sanjay does too', the meaning of the antecedent, 'Samir likes Kirit', can be represented as likes(samir) (kirit), while the meaning of the elliptical expression 'Sanjay does too' is simply $P$ (sanjay) — where, simplifying, $P$ can be thought of as something like the property of DoING. Clearly, "that Sanjay does" is not what is
} 
that, then pragmatic determinants of what is asserted, stated, and said end up being absolutely ubiquitous: even elliptical speech acts of the most familiar kinds (e.g. B's utterances in (6) through (9)) would provide examples of pragmatics helping to supply a property (symbolized in Crouch, Dalrymple, and such by the recovery of a lambda-abstract) directly, without any mediation by underlying morphosyntactic structure. Clearly then, whatever its plausibility, this version of ellipsis is not what semantics-oriented theorists need either.

Given the foregoing, the broad sense of 'syntactic ellipsis' which is required for Stanley's critique (and with it the semantics-oriented project) to succeed is surely this: sub-sentential speech must be like the kind of ellipsis one sees within sentences (e.g. VP ellipsis and sluicing), in that there is hidden syntactic structure in both cases. There are, as noted above, two versions of ellipsis which fit that description, both of which would help the semantics-oriented theorist - if only they were truly applicable to such cases. First, it might be that there is unpronounced "ordinary syntactic material": nouns, tense markers, and the like which ordinarily have a pronunciation, but which somehow fail to be pronounced in this situation. Second, it might be that there are elements of syntax which never have a pronunciation, but which are syntactically present nonetheless. Taking the first road, sub-sentential speech is explained away as being rather like VP ellipsis ('Maria likes milk, but Jaime doesn't') as this was understood by, say, Sag (1976). That is, the speaker intends what is at one level a complete(ordinary) sentence, and this is what the hearer recovers; but what the speaker pronounces, and what the hearer hears, has been abbreviated by some kind of grammar-driven deletion process. To take an example, the idea would be that the speaker who appeared to utter the phrase 'From Spain' in fact

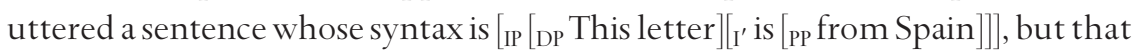
all that was pronounced was /frəm spein/. Taking this first road, ordinary syntactic material must be recovered in order for the hearer to find the expression actually produced. The second alternative is to explain away apparent

asserted. To determine what is asserted, the hearer must reason roughly as follows. Given that 'Samir' and 'Sanjay' are syntactically parallel expressions, whatever (more specific) property goes in for $P$ should render true the equation $P($ sanjay) $=$ likes (samir) (kirit). The salient solution is clearly $P=$ $\lambda x$.likes (x, kirit). Taking this, rather than DoING itself, as the value for $P$ in the meaning of the elliptical expression, we get likes(sanjay) (kirit). This is what is asserted. Notice that, putting things roughly, it is the unhelpful meaning of 'does too', rather than some hidden syntax, which causes the hearer to embark on this search; and what she looks for is not a natural language predicate, but a suitable property. Thus ellipsis in the sense of Higher-Order Unification does not avoid the consequences of the pragmatics-oriented view, presented at the outset; it just arrives at the same consequences by a somewhat different route. 


\section{2 / Robert J. Stainton}

sub-sentential speech as the production of elements vaguely similar to "big PRO”, as posited in Government and Binding Theory. (The postulated element couldn't actually be PRO as classically construed, for reasons that will emerge below.) The hypothesis here would be that the speaker uttered a sentence whose syntax was, say, [IP [DP PRO $]_{\mathrm{I}^{\prime}}$ (light-verb) [PP from Spain]]]. Again, this is pronounced / from spein/. On the second version, the task is not to recover unpronounced ordinary syntactic material; it is to find a contextually salient non-linguistic referent for the empty element PRO and for the unpronounced light-verb.

The versions of "ellipsis" presented above may be summarized with the following tree:

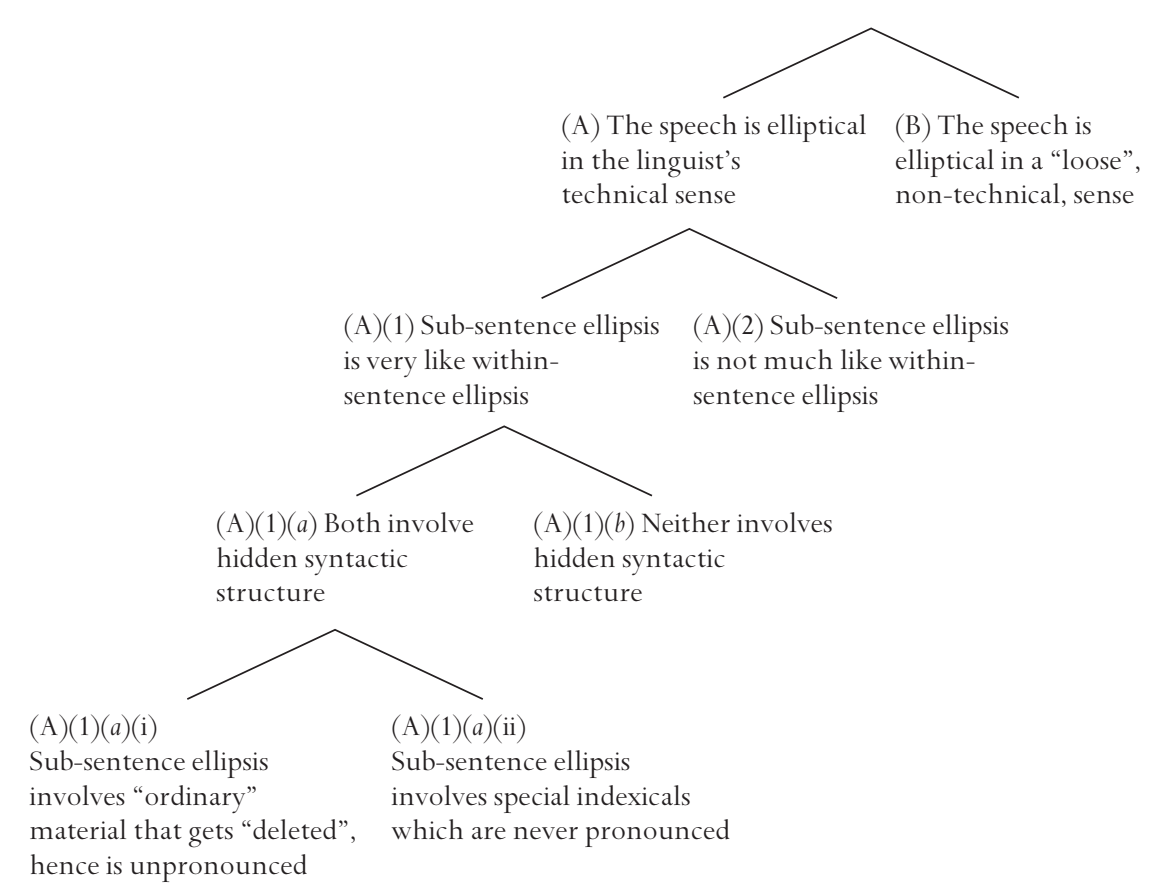

And the key conclusion can be put this way: what Stanley et al. need is for one of (A)(1)(a)(i) or (A)(1)(a)(ii) to be true. Discussing these two proposals is thus sufficient, for my purposes, because none of the other versions of ellipsis meets (14), repeated below:

(14) The Not-Just-Recasting Constraint. If the speech act is syntactically elliptical, then it's not a case of pragmatics determining what is asserted, and it's not a case of integration occurring outside the medium of spoken language. 
The remaining question is: When 'syntactic ellipsis' is read in the ways required, is it plausible that syntactic ellipsis really is occurring? This question will be a central focus of the rest of my discussion. I will address it in two steps. First, I will consider (A)(1)(a)(i) above, "the deletion story", and explain why it is not plausible that anything like what (the deletion theorists maintain) occurs in VP ellipsis and sluicing is occurring when speakers (appear to) speak sub-sententially. Second, I consider whether it's plausible that (A)(1)(a)(ii), "the empty element story", is responsible for the appearances. My overall conclusion is that no version of ellipsis meeting the Constraint can plausibly be extended to non-sentential speech.

\section{Replies to Stanley}

Before turning to my replies, it will be useful to briefly recap. In Section 1 I introduced two broad approaches to sub-sentential speech. The pragmatics-oriented approach treated the phenomenon as genuine, and had pragmatic processes of varying sorts bridging the gap between what the sub-sentential expressionuttered means (i.e. something sub-propositional) and what the speaker meant (indeed, stated) in so speaking (i.e. something fully propositional). The semanticsoriented approach, in contrast, treated the appearances as illusory, claiming that covert syntax of some kind made it the case that the expression-uttered was, despite appearances, fully propositional after all — at least once all syntactically provided "slots" were filled. Having distinguished the two approaches, I highlighted two reasons why it matters who is right. First, there are consequences for where to draw the semantics-pragmatics boundary - in particular, consequences about whether there really are pragmatic determinants of what is said. Second, there are consequences for cognitive science, having to do with how information gets integrated during speech comprehension. In Section 2 I briefly surveyed some of my earlier arguments against the semantics-oriented approach, and introduced a multifaceted reply that Jason Stanley offered to defend the semantics-oriented approach. In particular, Stanley suggested that a "divide and conquer" strategy — treating some cases as not genuinely assertoric, some as syntactic ellipsis, and some as shorthand - would allow the semanticsoriented theorist to explain away all apparent cases of sub-sentential speech acts. In Section 3, as a preliminary to my reply to Stanley (and to Ludlow), I canvassed a variety of things that one might mean by 'ellipsis'. I argued that only two of those would actually rescue the semantics-oriented approach: the others are 


\section{4 / Robert J. Stainton}

either mere promissory notes, or else, in one fashion or another, they grant the consequences of the pragmatics-oriented approach. What remains is (a) to respond to Stanley's "divide and conquer" objection, including (b) critically discussing in detail the two familiar senses of 'ellipsis' that really would help the semantics-oriented theorist; and (c) to revisit at length the implications of taking sub-sentential assertion to be a genuine phenomenon. I turn to those issues now.

I think Stanley is unquestionably wrong that there aren't any examples left of genuine non-sentential speech acts, once his "divide and conquer" strategy has been applied. For instance, I believe that all three examples introduced at the outset - 'Chunks of strawberries' as said by Meera, 'Rob's mom' as said by Anita, and 'From Spain' as said by the person holding the letter - are immune to this three-pronged strategy. They aren't shorthand, in any sense that would save the semantics-oriented approach. They aren't ellipsis - again, not in any familiar sense that doesn't just recast the pragmatics-oriented view. And they are genuine speech acts. I will defend this view by discussing each sub-strategy in detail. I discuss Stanley's three "prongs" in reverse order. Section 4.1 will deal with both the appeal to "shorthand" and the claim that much of non-sentential speech is somehow not properly linguistic. Section 4.2 will address at length the deletiontype variant of syntactic ellipsis. Section 5 will focus on the empty element variant of syntactic ellipsis, as recently defended by Peter Ludlow.

\subsection{Shorthand and Not-an-Assertion}

The appeal to "shorthand" can be put aside quickly here. First, Stanley does not say nearly enough to make this a genuine proposal. Second, all of the ways of spelling out the proposal either merely recast the pragmatics-oriented view in other terms, or are subject to very serious problems. (See Elugardo and Stainton $2004 b$ for detailed discussion.) Third, Stanley himself (personal communication), in light of these considerations, has now given up the idea that "shorthand" can be usefully appealed to.

As for the second prong, we saw that Stanley suggests that many alleged cases of non-sentential assertion lack determinate propositional content, and determinate illocutionary force, and hence are not genuine assertions after all. His example, recall, is 'Water', as spoken by the thirsty man. The first thing I want to say is that, precisely in so far as there really is an indeterminacy, this is an unhelpful example. It would have been better to address directly the sort of cases I have always presented, where the idea that there is no determinate 
propositional content is highly implausible. In those cases, the content conveyed is just as determinate as in the vast majority of wholly sentential speech. Thus suppose the thirsty man had said 'A nice tall glass of water with three cubes of ice and a slice of lemon'. It is simply absurd to suppose that such an utterance is not "genuinely linguistic" - to suppose that, content-wise, this communicative act is more akin to a kick under the table than to an utterance of a complete sentence. But this phrase could easily be used when approaching the street vendor, with no special signals or prior discourse, just as easily, in fact, as 'Water' itself was imagined to be used.

By way of rubbing this in, consider some features of non-sentential speecheven in discourse initial position, and without gestures or other actions that might make a linguistic string salient:

(a) speakers can produce, and hearers can understand, an unlimited number of words or phrases, including absolutely novel ones like 'Another healthy dollop of that fruity whipped cream from Switzerland';

(b) the meaning of the expression is recursively compositionally determined;

(c) the thoughts communicated can be terrifically complex and subtle, indeed just as complex and subtle as the thoughts communicated by complete sentences;

(d) systematic changes in the words used yield systematic (and very fine-grained) changes in the meaning communicated;

(e) someone not wholly competent in the language in question often cannot understand these sorts of speech acts, precisely because they lack this competence;

$(f)$ the things used exhibit features like structural ambiguity, logical relations, etc., as well as exhibiting degrees of grammatically, speech-specific errors, and other hallmarks of syntactic items;

(g) a person who suffers from an aphasia will (typically) have not just their sentential speech, but also their non-sentential speech, altered in quite specific and systematic ways. (For example, if a patient lost her ability to understand fruit-words, she would cease to understand both the sentence 'Give me three red apples' and the unembedded phrase 'Three red apples'. $)^{15}$

15 Speaking of aphasias, there appear to be lesions and genetic abnormalities that specifically attack the ability to use and process syntactically complete sentences, but which leave the use and comprehension of sub-sentential speech (and especially single-word speech, whether containing free and bound morphemes or otherwise) more or less intact. Elugardo and Stainton (2003) argue, tentatively, that in such cases it is far less plausible that speakers and hearers are covertly processing sentences; and that, if this is not happening in the abnormal case, there is less reason to believe that sentential processing happens in the normal case either. Some relevant clinical cases and theoretical discussion of different sub-varieties of aphasics manifesting this and related symptoms may be found in Breedin and Saffran (1990), Chatterjee et al. (1995), Jarema (1998), Nespoulous et al. (1988), Sirigu (1998), and Varley (1998). 


\section{6 / Robert J. Stainton}

This list could go on. Indeed, think of just about any feature which distinguishes human speech from other types of communication. That feature is very likely to be exhibited by communication that is less-than-sentential-essentially because, from the point of view of the "language module", the only difference between non-sentential speech and sentential speech is that the former involves the use of projections from lexical categories, of semantic type $\left.\left.\left\langle_{e}\right\rangle,\right\rangle_{e, t}\right\rangle$, $<<e, t>, t>$, etc., while the latter involves the use of a projection from an inflectional element, assumed to be of semantic type $<_{t}>$. This surely is not akin to the difference between language use on the one hand, and under-the-tablekicks on the other. Moreover, to classify cases of non-sentential speech as "not genuinely contentful" would be to set a truly ubiquitous (and, as Barton 1990 notes, a highly grammatically constrained) speech phenomenon outside the bounds of language proper. Pick up any novel, listen to the radio or TV, read magazine or subway ads - and sub-sentential speech will jump out at you. Thus, all of the following appeared in a recent advertising flier (for a pharmacy), in the Ottawa Citizen:

(15) Recommended for ages 6 and older.

(16) Effective medicine for pain.

(17) Nicorette plus. Stop smoking aid. $4 \mathrm{mg}$. For smokers of over 25 cigarettes per day.

(18) 2nd set of prints. Everyday. \$1.99 for 36 exposures.

(19) For temporary relief of minor aches and pains.

As I will continue to argue in Section 5, these are no less bearers of semantic content than maximal projections of INFL, i.e. sentences in the syntactic sense. (Nor will it do to say that these are ungrammatical slips of the tongue, since they exemplify "edited language use", in particular a published form thereof!)

Nevertheless, I can imagine an argument that sub-sentential utterances do not amount to authentic assertions - not in terms of lacking both propositional content and force, but solely in terms of lacking force. (It is not an argument to be found in Stanley; but it's worthy of discussion nonetheless.) In particular, an opponent of my positive view could argue as follows:

The illocutionary force of an expression token is inherited from the illocutionary force assigned to its type. (Call this the "force-inheritance principle”.) But sub-sentences (the types, that is), including syntactically quite complex ones like (15)-(19), do not have illocutionary force. (For example, 
they do not have, as part of their expression-meaning, any kind of standard use - e.g. used-to-ask.) In which case, tokens of these cannot have illocutionary force either. Therefore, lacking determinate force, they are not genuine linguistic acts.

In response to this line of argument, note that whether the force-inheritance principle is true is not something that one simply stipulates; rather, we must look at speech instances, assess whether they have illocutionary force, and on this basis either verify or falsify the principle. To my mind, non-sentence cases falsify it.

But simply saying this would seem to leave my opponent and me at an impasse. For, what he or she may want to say is that, to the contrary, one can employ the force-inheritance principle to evaluate whether an utterance genuinely exhibits illocutionary force. Intuitions that run counter to this principle should be overruled on theoretical grounds. Applying the principle, my opponent could then conclude that non-sentential speech acts do not exhibit force. ${ }^{16}$ And hence that there are no non-sentential assertions.

One way out of this apparent impasse is to ask "Why does it matter whether something really is an assertion?" Reflecting on this question may give us a (rough and ready) test, a way of telling whether something has illocutionary force - independently of brute intuitions about whether something like 'From Spain', said of the letter, is an assertion. Now, I think assertion matters for comparatively practical reasons. Which isn't to say, of course, that non-assertions (e.g. mere implicatures) lack practical consequences - assertions just have different practical consequences. In particular, one can justifiably be accused of lying, and not merely misleading, only if one has asserted something falsewhich can leave one open to (easier) libel suits, stricter contractual obligations, perjury convictions, and so forth. ${ }^{17}$ One reasonable test, then, for whether an utterance is an assertion or not might have to do with its special practical (including legal and moral) consequences. Suppose that's right. (If it's not right,

${ }^{16}$ An exception might be made for word or phrase types that carry special intonation. For instance, one might think that the type 'From Spain?', with rising intonation, has illocutionary force. But if these are exceptions, they are ones which work against Stanley. I'll ignore the issue here.

${ }_{17}$ As Stanley pointed out to me in conversation, it is by no means true that assertion is the only kind of communication which can get one in legal or moral hot water. Merely conveying, in a way that isn't lie-prone, can also have legal and moral implications. For instance, to develop an example of Stanley's, suppose I am an alleged gangster on trial, who catches a juror's eye. First, I give a thumbs up, followed by rubbing my thumb and index finger; then, I give a thumbs down, followed by mimicking the firing of a gun with my hand, in the juror's direction. Here I may convey some kind of 


\section{8 / Robert J. Stainton}

I begin to lose a grip on why one should care about the determinants of what is asserted, stated, or said - since it would then appear that 'what is asserted' is used in some special sense, divorced from its ordinary implications.) Now, imagine a used car salesman who says, of a car whose odometer reads 10,000 kilometers, 'Driven only 10,000 kilometers. Like new.' Suppose further that, as the salesman well knows, the odometer reads thus because the car has been driven $1,010,000 \mathrm{~km}$, so that the meter returned to zero some months before, and then climbed up to 10,000 again. Has the salesman lied in this case? Or did he merely mislead? Clearly, say I, he lied. If the prospective buyer foolishly pays cash and doesn't get the details written down, can the verbal contract later be overthrown, on the grounds that it was framed on the basis of a lie? Or can the salesman say: "I didn't tell him that it had only been driven 10,000 kilometers. In fact, I didn't make any kind of statement at all, because I spoke sub-sententially. In particular, I made no claim about how worn-in the car was. The buyer just drew his own conclusions." Clearly, I think, the contract is vitiated by the lie, despite the sub-sentential nature of the speech act-just as it would have been if the salesman had instead uttered the complete sentence 'That car has only been driven 10,000 kilometers'. Now, despite certain uses of it sharing in the legal and other practical consequences specific to assertion, no force attaches to the expression type 'Driven only 10,000 kilometers'. Hence, as cases like this show, the force-inheritance principle is doubtful. But then one cannot use it to argue that non-sentential utterances lack illocutionary force.

Summing up so far, non-sentential speech typically exhibits determinate propositional content. The content may be vague, of course. But much of the time, it is not so vague as to make it "indeterminate" in the sense in question, i.e. such that it is robbed of being a genuine speech act. One need only glance at a magazine, or listen to the radio, or attend to casual speech, to find very large numbers of examples of sub-sentential speech with determinate propositional content. ${ }^{18}$ Moreover, putting aside a few quite special examples (e.g. 'Water' as said by the thirsty man), no reason has been given to think that sub-sentential

message, about a reward versus a punishment — sufficiently so that I may be convicted of attempting to tamper with the jury. But, it seems, I made no assertion. Be that as it may, my point remains: assertion, and saying what could be an actual lie, do play a central and distinctive role in some kinds of legal or moral disputes.

18 The proportion of sub-sentential speech in a corpus of interactive conversation among 10- to 12-year-olds turned out to be nearly a third, not including the ungrammatical stops and starts. Assuming this particular corpus was even somewhat representative, we may conclude that subsentential speech really is ubiquitous. (Parts of the corpus appear in Stainton and Hillier 1990.) 
utterances only appear to have illocutionary force. ${ }^{19}$ Certainly uttering onei.e. speaking sub-sententially — can make it the case that one has lied, committed perjury, or incurred a highly specific contractual obligation.

And besides, it's not as if all genuine sentential speech acts have to exhibit "determinate illocutionary force". Surely an immigration official may utter 'Foreigners must present their passports before boarding', this act sitting somewhere between an assertion and an order - without her utterance ceasing to be a speech act. Or suppose a professor produces an utterance of 'I will give you a B on that paper', such that it's unclear from context whether it is a statement, a promise, or a threat. Does it simply have to be exactly one of these, if it is to qualify as a speech act at all? Surely not. In these and many other cases it seems to me possible to have "genuinely linguistic" activity, but not a unique and determinate illocutionary force. But then the same lesson should apply to less-thansentential speech: even when there isn't one determinate force, there may still be a speech act. (If that's right, then even the utterance of 'Water' by the thirsty man might, when all is said and done, provide an example of a genuine sub-sentential speech act - even if it isn't determinately an assertion, a request, or a command.) In sum, at best a few examples of (allegedly) non-sentential assertion can be explained away by the "not genuinely linguistic gambit". So, there remain a whole host of examples of less-than-sentential speech that cannot be explained away. Except maybe by syntactic ellipsis. That will be the central focus of the remainder of the chapter, starting with the deletion-type theory.

\subsection{Syntactic Ellipsis, 1: Reconstruction of "Ordinary” Syntactic Material}

A key step in settling the issue of whether the first "syntactic ellipsis gambit" can really help avoid pragmatic determinants of what is literally asserted is to recall the notion of a discourse initial utterance. There is, as Stanley notes, both a broad and a narrow sense of this notion. On the narrow sense, an utterance is discourse initial if it is the first explicitly spoken utterance. Thus, in this narrow sense, Stanley's example of 'A world famous topologist' was discourse initial.

\footnotetext{
${ }^{19}$ In fact, even 'Water' can be used to make an assertion. Suppose someone with a very poor sense of smell is looking for water to put into her car's near-empty radiator. I help her out by sniffing at some substance that we find sitting by the side of the road, in a large plastic tank. I discover, from the smell, that it is probably alcohol, or some other highly flammable substance. Nevertheless, being poorly disposed to the woman with the deficient nose, I say 'Water'. This clearly was neither a question, nor an order. Rather, it was a (false) assertion.
} 


\section{0 / Robert J. Stainton}

In contrast, on the broad sense, an utterance is discourse initial only if there is neither any previously spoken expression, nor any expression which is otherwise made salient by the speaker. Obviously then an utterance could be discourse initial in the narrow sense, because nothing has yet been said, but not discourse initial in the broad sense - because of, for example, pointing gestures, arching of the eyebrows, etc. Indeed, this is precisely what Stanley says about the utterance of 'A world famous topologist'.

The question now is, Which of these (if either) tests for syntactic ellipsis? Or more precisely, which tests for ellipsis of kind (A)(1)(a)(i), in which it is ordinary syntactic material that somehow goes unpronounced? Stanley argues that being discourse initial in the broad sense is not a useful test. In fact, I agree. As will emerge when I discuss Hankamer and Sag type cases, being able to so appear doesn't prove that something is non-elliptical. What's more, lots of things which I take to be non-elliptical (e.g. an unembedded use of 'From Spain') often cannot occur without a significant amount of background preparation: both constructions involving syntactic ellipsis and most apparent examples of non-sentential speech cannot occur discourse initially, in the broad sense, because context must supply something to arrive at a complete proposition. ${ }^{20}$ Indeed, just to drive the point home, notice that infinitely many complete sentences are incapable of occurring felicitously without a large amount of background context. Here is one example. Though (20) can be felicitously used at the beginning of a discourse in the broad sense, the closely related and non-elliptical sentence (21) cannot so occur.

(20) A man was walking through New York City.

(21) He was walking there.

Thus this "test" fails in both directions. Therefore, I will not here take discourse initial position in this broad sense to be the appropriate diagnostic: it tells one almost nothing about the syntactic structure of the item under consideration.

${ }^{20}$ Moreover, the pragmatics-oriented proposal explains why sub-sentences (generally speaking) cannot so occur: in general, context must supply a talked-about object, property, or what-haveyou, to combine with the meaning of the word or phrase uttered. Typically, that is, using a bare word or phrase demands a "pragmatic controller": an extra-linguistic something referred to by the speaker. (More on this term below.) No background context, no salient object or property. No salient object or property, no felicitous use. Importantly, though, in this respect the use of an unembedded word or phrase is akin to the use of a non-elliptical, perfectly ordinary sentence that happens to contain explicit indexicals. (By the way, noting the need for a pragmatic controller in much sub-sentential speech shouldn't lead one to conclude that the things used, in such speech, actually contain pragmatically controlled indexicals, even covertly. See Sect. 5 for the reasons.) 
However, there is the other sense of "discourse initial". And that is the one which, I maintain, should be appealed to when evaluating this variant on the syntactic ellipsis theme.

That is, the appropriate sense of "discourse initial" is the narrow oneprecisely the one that I have employed in my previous writings on this topic. But there is a complication. The diagnostic is a bit more complex than "If it can occur in discourse initial position in the narrow sense, then it isn't elliptical." To get a grip on the complexities, and to see why this second "diagnostic" nevertheless ultimately works for this postulated variety of syntactic ellipsis, let me introduce some distinctions due to Hankamer and Sag (1976), who write within the "ellipsis-as-deletion" framework. I'll begin by quoting at length from their own "summary of conclusions":

1. Anaphoric processes divide into two classes: deep anaphora, in which the anaphor is not derived transformationally but is present in underlying representations; and surface anaphora, in which the anaphor is derived transformationally by deletion.

2. Some anaphoric processes accept pragmatic control and others do not. (All anaphoric processes accept syntactic control.)

3. The pragmatically controllable anaphors are just the deep anaphors....

5. Surface anaphora requires superficial syntactic identity of structure between the antecedent segment and the segment to be anaphorized; it does not require that the anaphor represent a coherent semantic unit.

6. Deep anaphora does not require that the anaphor be related to a superficially coherent syntactic unit, but it does require that it represent a coherent semantic unit. (Hankamer and Sag 1976: 421-2)

The terminology employed in this passage will be unfamiliar to many, so let me give some rough-and-ready glosses. "Pragmatic control" is essentially a matter of a deixis, i.e. a matter of a context-sensitive element taking on a semantic value by picking out some pragmatically salient non-linguistic element in the context. For instance, if I point at a woman and say 'She is a professor', this is pragmatic control. In other words, in pragmatic control, the pronominal expression can refer directly to something in the extra-linguistic context, rather than having to be explicitly tied to prior spoken discourse. "Syntactic control", in contrast, precisely involves some kind of "link" between a pronoun (or anything else which is appropriately context-sensitive) and a previous expression, so that the pronoun (or whatever) takes on the content of the linguistic item to which it is linked. Next, the link between the two kinds of control and "deep" versus "surface" anaphors. Hankamer and Sag takesurface anaphors to be (something like) derived "gaps" in an expression, brought about by (something like) deletion— such 


\section{2 / Robert J. Stainton}

that the "gap" in the resulting form is linked to a prior complete expression, the gap getting its content from the latter. ${ }^{21}$ Deep anaphors, in contrast, are context-sensitive pronouns (or whatever) that are base-generated. (This would include explicit pronouns or demonstratives, e.g. 'she', 'it', and 'that', as well as elements that remain unpronounced at the surface, like Government and Binding Theory's "big PRO”.) Now, Hankamer and Sag's central conclusion is that "deep anaphors" can be pragmatically controlled, but "surface anaphors" cannot be. The latter must be controlled syntactically. What's crucial for present purposes is that syntactic ellipsis — of the sort exemplified by VP ellipsis (e.g. 'She doesn't', 'No, John will') and sluicing ('I wonder who') — counts as surface anaphora. Elliptical sentence fragments are, in these cases, supposed to be derived by the deletion of redundant material. In which case, elliptical expressions require that the material omitted be explicitly spoken in prior discourse. Otherwise, the structures cannot be linked up appropriately. In contrast, expressions which contain indexical elements inserted in the base, such as 'She is a professor', can be "pragmatically controlled": they can get their content not only parasitically, by linking up with prior linguistic material, but also directly, by linking up with the environment. Suppose this is right. Given this, the absence of a syntactic controller is diagnostic for syntactic ellipsis of the kind familiar from VP ellipsis and sluicing: if there is no syntactic controller, then it isn't truly syntactic ellipsis in this sense. ${ }^{22}$

It is true that some theorists are now suspicious of this contrast. Some think that, in all cases, there isn't hidden syntactic material at all — whether linked to prior overt linguistic material, or linked to non-linguistic stuff. Ellipsis, for such theorists, is neither surface anaphora nor deep anaphora, in the sense of Hankamer and Sag, because ellipsis isn't anaphora at all. This is the sort of view shared by Dalrymple et al. Taking this line will likely force one to give up the diagnostic, because both (apparently) sub-sentential speech and familiar kinds

21 What syntacticians call "gapping”, e.g. 'Sue loves chocolate ice cream and Phil cookies', is at best a sub-variety of this. So the word 'gap' may carry unwelcome (because so specific) connotations for some readers. The connotation is not intended. I should also issue the following warning: the relation between the "gap" and the item "linked to" need not be precisely that now assumed to obtain between an anaphor and its binder. For instance, the "linked to" item may merely provide, at some later derivational stage, the material that gets reinserted at the gap site. This would equally count as syntactic control, in the intended sense.

22 As they put it elsewhere (Hankamer and Sag 1976: 406), "It is just those anaphoric processes that involve syntactic deletion at a superficial level of structure that require syntactic control." Or again, "It is just those anaphoric processes which consist in syntactic deletion, leaving no pro-form in place of the deleted structure, that require syntactic control" (Sag and Hankamer 1977: 122). 
of ellipsis (e.g. VP ellipsis and sluicing) will be subject only to "pragmatic control”. But, as noted, taking this line will ipso facto yield many cases of pragmatic determinants of what is asserted, stated, or said, and many cases of integration of non-linguistic content which does not involve translation into natural language syntax. So, taking this route, Stanley and the semantics-oriented theorists would win a battle (i.e. over tests for syntactic ellipsis) only by losing the war. Others think that VP ellipsis and such always involve a covert deictic element, so that it's not a matter of surface anaphora after all. This view would save the semantics-oriented approach, as noted: this just is version $(A)(1)(b)(i i)$ of syntactic ellipsis, introduced in the last section, but put in other terms. It will be discussed below. But, in so far as the framework for syntactic ellipsis remains that of Sag and the like, this contrast ought to be accepted, and so should the concomitant diagnostic.

The idea then, by way of summary, goes like this:

(P1) Surface anaphora requires a syntactic controller.

(P2) Syntactic ellipsis, understood as deletion, is a sub-variety of surface anaphora (precisely because it arises from deletion, or some such).

(C1) Syntactic ellipsis, understood as deletion, requires a syntactic controller. (From P1 and P2)

(P3) In discourse initial situation in the narrow sense there is no prior linguistic material at all, hence no syntactic controller.

(C2) In discourse initial situation in the narrow sense, syntactic ellipsis, in the sense of deletion, is not possible. (From P3 and C1)

If $\mathrm{C} 2$ were true, it could be used to show that what appears to be non-sentential speech really is non-sentential, when there is no actually spoken prior linguistic material. (Assuming, that is, that the other variant of syntactic ellipsis is equally implausible.) For, in discourse initial position in the narrow sense, there can be no prior material for any supposed "gap" to link to, precisely because nothing has yet been said. Unfortunately, as I've said, things are empirically a bit more complicated than this. The fact is that even "surface anaphors", the kind which do ordinarily require syntactic control, can (under very special circumstances) occur without the appropriate material — though when they do so appear, they sound rather awkward. Thus, borrowing still from Hankamer and Sag (1976: 408), suppose that nothing has yet been said as two people (say Jorge and Ivan) walk onto an empty stage. Jorge, without speaking a word, produces a gun, points it into the distance, and fires. This is followed immediately by an agonized scream somewhere off in the distance. In this quite extraordinary 


\section{4 / Robert J. Stainton}

circumstance, Ivan can say 'I wonder who', and be understood as meaning 'I wonder who screamed'. Crucially, however, his utterance has a highly marked flavor. (Many theorists even label it ungrammatical. See, for example, Tanenhaus and Carlson 1990.) So the caveat to C2 is this: it holds unless circumstances are quite exceptional; and when it doesn't hold, i.e. when such exceptional circumstances obtain, the utterance is highly marked, or even ungrammatical.

In light of this, one can reconstruct the following test from Hankamer and Sag's discussion:

(22) HESS-inspired diagnostic. If an expression can be used in discourse initial situation in the narrow sense when circumstances are not especially exceptional, then that is evidence that it is not syntactically elliptical in the sense countenanced by deletion-type theories. Moreover, if a use of the expression in discourse initial situation in the narrow sense does not sound especially marked, then that too is evidence that the expression is not syntactically elliptical in this sense.

Now, let's apply this to utterances of plain old words and phrases. They can occur as freely in discourse initial position, in the narrow sense, as indexicalcontaining complete sentences. Indeed, they routinely so occur. And, unlike speech errors and false starts, they routinely occur in discourse initial situation, even in carefully edited published documents. Moreover, discourse initial uses of words/phrase do not sound the least bit awkward to the unbiased ear. ${ }^{23}$ Hence there remains a real difference between syntactic ellipsis in sense (A)(1)(a)(i) a variety of "surface anaphora" — and (what I call) the use of ordinary words and phrases.

Hankamer and Sag's distinctions being on the table, it should be clear that while occurring discourse initially in the narrow sense is sufficient for there being no syntactic controller, so occurring is not necessary for there being no syntactic controller. Sometimes there won't be a syntactic controller, in their sense, even when a discourse is ongoing. Hence the real issue isn't "Can (apparent)

${ }^{23}$ Granted, sub-sentential speech might, during explicit reflection on its use, distress individuals whose intuitions have been shaped (dare I say "warped"?) by lessons in "proper grammar". Such speakers may find - or may claim to find - the use of words and phrases in isolation to be highly marked. Given the constant and utterly unnoticed use of sub-sentences, however, even by such speakers, I put such conscious reflections aside as misleading and irrelevant to descriptive linguistics. (Compare claims that it is awkward to begin a sentence with 'and', or ungrammatical to end an English sentence with a preposition. At best, sub-sentential speech is "awkward", "marked", or "ungrammatical" in only this strained, prescriptive, sense.) 
non-sentences occur discourse initially?" Rather, the real issue is "Can (apparent) non-sentences occur without a syntactic controller?” Before addressing that question head-on, I propose a not-so-brief interlude, to spell out in greater detail what a syntactic controller is supposed to be within this kind of framework, and to explore why syntactic ellipsis, in sense (A)(1)(a)(i), really does require one. This will allow me to greatly sharpen the question of whether ellipsis in sense (A)(1)(a)(i) is plausibly going on in (apparent) cases of sub-sentential speech, and to give that question a pretty definitive (negative) answer.

Consider two general features of syntactic ellipsis. First, whenever syntactic ellipsis-understood-as-deletion occurs, it must be possible for the hearer to recover the material omitted. Otherwise, such ellipsis would get in the way of the hearer's comprehension of what was said. Second, syntactic ellipsis, if it is to help Stanley resist pragmatic determinants of what is said, must be a grammatical rule, a rule of syntax. It must operate, to use the familiar jargon, "within the language faculty". Thus, though ellipsis in this sense is subject to the constraint that the hearer can understand what the speaker meant, in speaking elliptically, it is also subject to additional, specifically syntactic, constraints. (Thus familiar issues of grammaticality will arise, above and beyond any issues of interpretability.) More than that, ellipsis, at least the kind exemplified by deletion-type treatments of VP ellipsis, sluicing, and such, is a matter of syntactic derivation, not a matter of "guesstimating" (using abduction or some such) what expression the speaker probably uttered. It is fast and automatic . . . essentially algorithmic. It is also, like syntactic operations generally, very likely to be informationally encapsulated, in Fodor's (1983) sense: qua rule of syntax, ellipsis does not have access to all of the information available to the agent. In particular, rules of syntactic ellipsis, as captured by (A)(1)(a)(i), do not make use of: knowledge of beliefs shared by the speaker and hearer; general information about the world, stored in longterm general-purpose memory; knowledge about the topic of conversation, its general direction, or its specific aims; etc. Nor, I would hazard, can rules of syntactic ellipsis so understood make use of information from other perceptual modes. In which case, rules of syntactic ellipsis in this sense do not interact with information about the current physical context.

Consider now an important implication of these two features, namely, the requirement of recoverability and the autonomously grammatical nature of the process. If reconstruction of the elided material is to be properly syntactic, then there must be sufficient linguistic material for the reconstruction rules to operate on. This will allow the hearer, on linguistic grounds alone, to reconstruct 


\section{6 / Robert J. Stainton}

the unique and precise sentence uttered by the speaker. ${ }^{24}$ Call this the Constraint of Syntactic Recoverability. Syntactic ellipsis, given this constraint, cannot happen freely: an entry condition for the rule's application is that the Constraint of Syntactic Recoverability be met. To see how a deletion-type account of syntactic ellipsis meets this constraint, let me give a rough sketch of such an account. (What follows abstracts away from many details. But I hope it gets the key points across.) Syntactic ellipsis, so conceived, involves two sentences, and some sort of operation. The first sentence, sometimes called the "trigger sentence", is actually spoken, and hence available "in the hearer's language module". There is also a "target sentence", the one to which the operation applies. It is not spoken, at least not in its entirety. Rather, only a fragment of it, call it the "remnant", is actually pronounced by the speaker. For example, in (8) the trigger is 'Who lives in Madrid', the target is 'Juan lives in Madrid', and the remnant is 'Juan does'.

(8) A: Who lives in Madrid?

2B: Juan does.

Crucially, to repeat, the target is not pronounced. The fundamental problem for a theory of ellipsis of this kind is then to explain, in a precise and explicit way, how something which doesn't sound like the target sentence-here, 'Juan does' - nevertheless shares the interpretation of the target sentence, 'Juan lives in Madrid'. The usual answer is this: the meaning of the pronounced bit comes from the target sentence itself, the thing that the remnant - the thing actually pronounced - is derived from. Given this, the hearer's job is to reconstruct the target sentence, on the basis of the trigger and the part of the target which is actually pronounced. Recovering the target, which is what endows the

${ }^{24}$ It has generally been assumed that syntactic identity (or near identity) is required between the antecedent and the material to be elided. Indeed, this requirement of "syntactic parallelism" has been experimentally supported: see Tanenhaus and Carlson (1990 and elsewhere). As they note, the requirement accounts for the experimentally robust difference between (the parallel) 'It always annoys Sally when anyone mentions her sister's name. However, Tom did anyway out of spite' and (the non-parallel) 'The mention of her sister's name always annoys Sally. However, Tom did anyway out of spite'. (Interestingly, Tanenhaus and Carlson 1990 not only found that syntactic parallelism has an impact on "make sense judgments" when subjects are processing surface anaphors, they also found that syntactic parallelism or lack thereof does not make a significant difference to "make sense judgments" when subjects are processing deep anaphors. They take this to be evidence of the psychological reality of Hankamer and Sag's contrast between deep and surface anaphors.) The requirement of syntactic identity (or parallelism) is not universally accepted, however. In particular, Jason Merchant (2001) has persuasively argued that what matters is something more like identity of semantic content. 
utterance with its meaning, allows the hearer to understand what was literally said.

That's the general picture. Here, in a bit more detail, is how this is supposed to be achieved. Within the trigger and within the target there are elements which, at some level (usually thought to be LF), are qualitatively identical. Taking another example, the trigger might be 'Juan lives in Spain', and the target 'He doesn't live in Spain'. It's hypothesized that, corresponding to 'lives in Spain' (the element in the trigger) and 'live in Spain' (the element in the target), there is (again, at some level) a structure shared by both. For instance, the LF [live in Spain] might be thought to be the "identical material" in question. When the trigger and the target share this "identical material" at LF, a highly constrained syntactic operation applies, which leaves the (straightforward) remnant of the target sentence. On one variant, due to Sag (1976), the rule deletes from the target sentence the surface material corresponding to the "identical material". In the example at hand, the input to the rule is the target sentence's surface structure, 'He doesn't already live in Spain', and the output is the surface remnant, 'He doesn't' - again, under the condition that 'already live in Spain' has an LF exactly identical to the LF of the corresponding element in the trigger, namely 'already lives in Spain'. Looked at from the hearer's perspective, she hears the remnant as well as the trigger sentence, and uses them-applying the operation in reverse, as it were- to rebuild the target sentence. The recovered target sentence then supplies the interpretation of the utterance.

Now, the trigger sentence, in this picture, is a specific example of what Hankamer and Sag termed a "syntactic controller". And it should now be clear why syntactic ellipsis, on this kind of story, requires such a thing: without it, the Syntactic Recoverability Constraint would likely be violated.

At last I return to the question at hand: "Can (apparent) non-sentences occur without a syntactic controller?" Given the foregoing, this question can be sharpened, since it is now pretty clear what features a syntactic controller for syntactic ellipsis must have, on this kind of story. Those features are summarized in (23):

(23) A syntactic controller for syntactic ellipsis, in the sense of (A)(1)(a)(i). An explicitly occurring sentence containing (at some level) material identical with the material deleted from the target sentence. This sentence must be such that, together with a straightforward remnant of the target, it permits a deterministic and highly grammatically constrained, syntax-based, recovery of the precise target sentence - without the use of general purpose inference, or information not available to the "language module". 


\section{8 / Robert J. Stainton}

Is it the case that, in most instances of less-than-sentential speech, there is a syntactic controller, so described? Absolutely not. In particular, in none of the examples given in my writings on this topic was there a syntactic controller for the alleged examples of less-than-sentential speech. Moreover, the examples I considered aside, even in cases where there is an item that would fit the bill, it clearly isn't required. In contrast, genuine syntactic ellipsis, on this kind of account, demands a syntactic controller, in this highly technical sensebecause without one, the Syntactic Recoverability Constraint will not be met. So, the use of sub-sentences cannot be reclassified as syntactic ellipsis in this sense.

It's worth the effort to introduce an example of speech which is not discourse initial, but such that there is still no syntactic controller in the requisite sense. Doing so will help make the point that this, and not discourse initial position per se, is the real issue. The following is a slightly modified ${ }^{25}$ variant of an example that is discussed at length by Ellen Barton. In it, B explains the White House staff's behavior in terms of their old grudge against O'Neill. The example is this:

A: The White House staff doesn't visit Tip O'Neill in his Congressional office.

B: An old grudge.

And here is what Barton says about this example,

[An ellipsis analysis cannot generate this NP, 'An old grudge', in this context] because the NP is not a demonstrably straightforward remnant of some previous sentence or question in the linguistic context, and any deletion rules generating such a structure would violate the Condition of Recoverability on Deletion. (Barton 1990, p. xiv)

Quite so. B's utterance cannot be treated as an elliptical sentence on familiar deletion-type accounts, because there isn't any target sentence from which it could have been straightforwardly derived, such that the target sentence would share "identical material" with the (supposed) trigger, the sentence uttered by A. So here we have a case of non-sentential speech, but not in discourse initial position in either the broad sense (which, as I've said, is not typically relevant to syntax), or the narrow sense (which at least seems to be highly relevant to syntax). It should be identified as non-sentential, and non-elliptical, because there is no syntactic controller in sense (23). And too, it clearly is a genuine speech act,

25 Barton's original (attested) example has B saying not 'An old grudge' but simply 'Old grudge'. The latter variant complicates matters, because it appears to be not an NP, but an N-bar constituent. Barton (1990) argues that appearances are misleading in this case, and that 'Old grudge', so used, really is a maximal projection. I remain unconvinced. In order to sidestep that debate, however, which is largely irrelevant to present purposes, I here insert the determiner 'An'. 
and it's not "shorthand". Thus we here have an example that cannot be reclassified in any of the three ways Stanley mentions.

Having said all this, it's worth returning to that earlier dispute, about whether it is the narrow or the broad sense of discourse initial that is wanted. Specifically, it's worth reflecting on why (22), repeated below, succeeds as a diagnostic where the broad sense of 'discourse initial' fails. Doing so will also bring out, still more clearly, the respects in which non-sentential speech is not syntactically elliptical in the sense here being discussed.

(22) HESS-inspired diagnostic. If an expression can be used in discourse initial situation in the narrow sense when circumstances are not especially exceptional, then that is evidence that it is not syntactically elliptical in the sense countenanced by deletion-type theories. Moreover, if a use of the expression in discourse initial situation in the narrow sense does not sound especially marked, then that too is evidence that the expression is not syntactically elliptical in this sense.

First, an obvious point. As I've just explained, true ellipsis, on this kind of account, involves deleting certain material under (quite complex) "conditions of identity" with material spoken in prior discourse. ${ }^{26}$ There is always a "trigger" and a "target", with some portion of the target being deleted (or otherwise rendered unpronounced) because of the presence, within the trigger, of the very same material (again, at some level, usually considered to be LF). ${ }^{27}$ Obviously, however, you can't have identity (of an element's underlying structure) with nothing. The trigger must exist. That is why discourse initial position in the narrow sense is a good diagnostic after all, at least if one adopts this theory of ellipsis: in that position, there is no trigger, no syntactic item containing material supposedly also found in some "target".

${ }^{26}$ Actually, deletion accounts are just one sub-class of theories which treat ellipsis as a syntactic process. As already noted, Williams (1977) offers a copying theory, according to which null elements ("deltas") are base-generated, such that material from prior discourse is linked to these null elements. Interpretation then involves copying the linked material into the site of the "delta". Here too, though, there can be no linking-and-copying in syntax if there is nothing appropriate, within the language module, for the "gap" to link to. So, albeit for different reasons, Williams's account also requires a syntactic controller for genuine ellipsis.

${ }^{27}$ Why "at some level”? Because, to take one example, the trigger can be 'Mary bought a gun', with the target 'She didn't buy a gun', and the resulting remnant being 'No, she didn't'. What is deleted from the target, notice, is not 'bought a gun', but 'buy a gun'—-despite the fact that this latter does not appear, on the surface anyway, in the trigger sentence. The thought, however, is that at some level, probably LF, the trigger and the target share the same material, [buy a gun], and this licenses deletion. 


\section{0 / Robert J. Stainton}

Now a less obvious point. It's reasonable to ask why gestures, arched eyebrows, and so forth cannot raise an expression to salience, so that the madesalient expression can then serve as the trigger, even without being explicitly uttered. Why not allow identity of underlying syntactic structure with some sentence which merely manages somehow to be pragmatically salient? A very good question. Here is the answer: following Barton (1990), I have proposed that true syntactic ellipsis in the sense at hand, like anaphora in the sense of contemporary Binding Theory, is a process that is resolved purely linguistically. Put in Fodor's terms, it is resolved within the language module: recovery of the unuttered material is a specifically linguistic process, not a pragmatic process; that is, ellipsis is not resolved in an all-things-considered sort of way, in the "central system"; in particular, apart from the highly marked cases discussed by Hankamer and Sag, it cannot involve the pragmatic process of the hearer "guesstimating" what the trigger sentence was. But then, to have a non-marked use, actual prior discourse of the right sort is crucial-because that is what allows the whole process to take place within the language module. In brief, if it's the whole agent who, holistically and all-things-considered, figures out as best she can what sentence was (supposedly) produced, rather than this process occurring in some special-purpose language module, then it isn't ellipsis in the sense familiar from the literature on VP ellipsis and sluicing. (Besides, it will very seldom be the case that a specific and determinate linguistic something is made salient in this way anyway. And true syntactic ellipsis in this sense patently requires that. ${ }^{28}$ )

To illustrate the difference between pragmatic "guesstimating" of a full sentence versus genuine syntactic ellipsis, recall the example of the commander who purportedly cabled 'peccavi' to his superiors. As the story is told, the commander wanted the recipients of the cable to translate this Latin sentence into the English equivalent 'I have sinned'. He further intended them to move from that English sentence to the homophonous English sentence 'I have Sind', thereby coming to understand that he had conquered the province in question.

${ }^{28}$ Curiously, Stanley and Szabó (2000) make just this point against a syntactic-ellipsis analysis of quantifier domain restriction. Roughly speaking they say, about an attempt to explain the domain restriction of 'Every bottle is empty' to just those bottles recently purchased by the speaker, that this sentence cannot be treated as an elliptical version of, for example, 'Every bottle I just purchased is empty', because "In cases of syntactic ellipsis, there is a unique phrase recoverable from context" (Stanley and Szabó 2000: 25). Quite right, say I. But I would have thought that precisely the same condition would apply to an ellipsis analysis of (apparently) sub-sentential speech. For an argument against deletion-type approaches to ellipsis on the basis of the "indeterminacy" of the supposed convert material, see Clapp (2001). See also Elugardo and Stainton (2001, 2004b). 
Patently, however, the mere fact that the speaker intended, and the hearers recovered, the sentence 'I have Sind' does not show that 'peccavi' is syntactically elliptical for 'I have Sind'. What makes this not a case of syntactic ellipsis is precisely that the "recovery" was not wholly linguistic, but instead drew on lots of background information - e.g. that the commander would not mean only that he had committed a sin, and that the commander was in the general neighborhood of Sind. Similarly, say I, if the "recovery" of the full sentence, in a case of sub-sentential speech, is not a grammatical derivation, but is instead just an informed guesstimate based on everything known by the agent, then the process is not syntactic ellipsis as this is standardly understood.

The results of this section on syntactic ellipsis can be summed up as follows. I first pointed out that if pragmatic determinants of what is said are to be resisted, the Constraint below must hold:

(14) Constraint. If the speech is syntactically elliptical, then it's not a case of pragmatics determining what is asserted, and it's not a case of integration occurring outside the medium of spoken language.

This, in turn, requires that syntactic ellipsis in a quite specific sense should be going on. In particular, there must be hidden syntactic material being processed. I then argued that one variant of ellipsis, of the requisite sort, is not occurring in nonsentential speech. Here I appealed to the fact that unembedded words and phrases occur without an explicitly spoken "syntactic controller" as freely as complete sentences do, and they so occur without awkwardness. In contrast, prototypical syntactically elliptical sentences can only occur without a syntactic controller in quite exceptional circumstances; and when they do so occur, they are highly marked - some would say ungrammatical. It is this feature that distinguishes genuine syntactic ellipsis from non-sentence use. What's more, I tried to make clear why genuinely elliptical constructions would require a syntactic controller on a deletion-type view: genuine syntactic ellipsis, on this view, would require that the hearer be able to recover, by a process of syntactic derivation, the complete sentential "source" of the fragment actually pronounced. But then elliptical constructions, if they are derived this way, cannot occur without adequate linguistic material as input to the derivation. To repeat, syntactic ellipsis in this sense - in sharp contrast with the 'peccavi' example-is not a matter of "guesstimating", on the basis of an all-things-considered inference, more or less what the speaker had in mind. (Besides, if it were a matter of drawing inferences in that way, wouldn't there once again be pragmatic determinants of what is asserted, stated, or said?) The job of the syntactic controller is precisely to supply 


\section{2}

\section{/ Robert J. Stainton}

(part of) the necessary input to this derivation. In contrast, words and phrases can occur without a syntactic controller precisely because there is no syntactic process of reconstruction. This is why, on this sort of account, non-sentences are predicted to behave so differently.

\subsection{Syntactic Ellipsis, 2: Empty Elements}

Given the last section, let us grant that non-sentential speech doesn't look at all like VP or CP deletion (a kind of "surface anaphora") as classically conceived, because the latter, if it exists at all, would require a syntactic controller. As a result, appeal to this variety of ellipsis will not save the semantics-oriented approach, because it is not empirically plausible that sub-sentence use requires a syntactic controller in the same way.

It also emerged in the last section, however, that sub-sentential speech does make extensive use of non-linguistic context. And precisely this observation may inspire another, quite different, variant of the ellipsis gambit. Maybe (apparently) isolated words and phrases are really syntactically more complex expressions that contain base-generated, phonologically null, context-sensitive elements. This is version (A)(1)(a)(ii) of ellipsis, the other version which actually would help the semantics-oriented theorist. ${ }^{29}$ To give the idea, let me lay out a specific proposal. Peter Ludlow (2004) suggests that many (possibly all) cases of apparent sub-sentential speech are really cases in which the expression uttered, at some level of representation, contains some subset of:

PRO in subject position;

an unpronounced "light verb” (e.g., 'have', 'do', etc.) in V;

OBJ in object position;

DET in determiner position.

He maintains, for example, that (24) is a possible syntactic structure.

(24) $[\mathrm{S}$ PRO (give) OBJ $[$ DET brick $]]$

This structure would be pronounced / brlk/, because none of the other syntactic items receive pronunciation. But, despite how it is pronounced, it is sentential nonetheless.

${ }^{29}$ I say "the" other version of ellipsis which would help the semantics-oriented theorist, but I should stress again that there could be novel accounts of syntactic ellipsis waiting in the wings, which would also do the job. Indeed, Jason Merchant, in empirically rich and inventive work in progress, is attempting to construct just such a novel account. Discussion of Merchant's very recent work on non-sentences, however, must wait for another day. 
Let's first be clear about how positing (24) and related structures would bear on the semantic versus pragmatic approaches to apparently sub-sentential speech. Imagine a case in which Alice, taking advantage of a very rich background context, seems to utter the word 'brick', and thereby manages to assert that Bruce gave Cammi the brick. This looks like a case in which there are pragmatic determinants of what is asserted. It equally looks like a case in which the hearer understands Alice without integrating contextual clues into a natural language expression of type $\langle t\rangle$. But suppose that what Alice really uttered, and what her interlocutor recovered, was (24). This syntactic structure is of semantic type $\langle t\rangle$. Roughly, its character is a function from three contextually supplied items - two individuals $x$ and $y$ (i.e. one each for PRO and OBJ) plus one determiner meaning for DET - to the proposition that $x$ gave $y$ some quantity of brick. Thus if Alice actually produced (24), rather than the noun $\left[_{\mathrm{N}}\right.$ brick], then Alice did not utter a sub-sentence after all. And the role of pragmatics was merely to find real-world referents for PRO, OBJ, and DET- - which is just another kind of slot-filling. Hence there aren't pragmatic determinants of what is asserted after all. And informational integration in this case, within the hearer, is occurring in natural language: by assigning referents to the empty elements.

That is the idea. Here is what I find problematic about it. My first objection is that the proposal leaves too much under-described. In particular, nothing has been said about where these empty elements can and cannot occur. Before taking this conjecture wholly seriously, we must be told, for example, what blocks 'р во broke овj', from being well-formed in English, and meaning, in the right context, that Fiona broke the pot. Equally, Ludlow must explain why 'Loves baseball' is fine as a sub-sentence. In its familiar incarnations, PRo is only supposed to be the subject of non-finite verbs; so what occurs as the subject of 'Loves baseball' cannot be Pro. (See Chomsky 1981 on the "Pro theorem” and finite verbs.) But the subject cannot be pro either, which is the empty element that appears as subject of finite clauses, since English is not a pro-drop language. Since this suggest that the structure here isn't 'Pro loves baseball' or 'pro loves baseball', what is it? It must be some third, wholly unfamiliar, empty element. Again, Ludlow needs to provide the licensing conditions for this new empty element.

The next objection runs rather deeper. When one posits empty elements in a given structure, a key methodological constraint must be met: reasons must be given for positing the element. In particular, the empty elements should explain things that otherwise go unexplained. This is not to say that empty elements are per se promiscuous. (Though many contemporary syntactic frameworks do, in fact, disallow "inaudibilia" in their entirety.) But to accept inaudibilia in some cases should not lead one to open the floodgates: in each 


\section{4 / Robert J. Stainton}

new case, the explanatory burden must be met. The problem here is, no compelling syntactic evidence has been given for positing PRO, OBJ, and DET in these structures. (More on this in the next section.) No psycholinguistic or other evidence has been offered either. Indeed, no evidence in favor of them has been given at all. As things stand, the only reason for positing these empty elements, in these cases, is merely to account for what the sound was used to say. Methodologically, I think it rather rash to move quickly from type meaning to syntax. (Positing covert syntax solely on the basis of semantic content was, I seem to recall, a cardinal sin of Generative Semantics.) It is equally rash to move quickly from literal utterance meaning, "what was asserted or stated", to context-invariant type meaning. ${ }^{30}$ The inference required here is thus doubly rash: we are asked to posit hidden syntax merely on the basis of what the speaker asserted and the hearer understood on a particular occasion. Moreover, there is no need to posit these items even on such feeble grounds: a pragmatic story — which is required anyway, to determine the referent of the alleged empty elementscan capture the observed usage without positing any extra syntactic structure.

Here is a way of making the point that these elements really are explanatorily otiose - until, anyway, specifically syntactic arguments can be provided for their existence. Taking a leaf from Kripke (1977), imagine a language, Lingesh, which sounds exactly like English, and has the same meanings assigned to all "ordinary" words, phrases, and sentences. By stipulation, however, empty elements of the kind proposed above do not exist. What looks like a word in Lingesh just is a word. Let's further stipulate that speakers of this language have, as a matter of fact, never once uttered anything but a maximal projection of INFL, i.e. a sentence in the syntactic sense. Now, consider what would happen if someone, say Angelika, chose to utter an unembedded phrase, while holding up some mail. Say she utters the plain old phrase 'From Spain'-where, as in English, this phrase is assigned as its semantic value that property shared by all and only things from Spain. Could Angelika be understood to have communicated the proposition that the displayed letter was from Spain? My very strong intuition is that she could be so understood. What this suggests is that even without introducing empty elements, sub-sentential communication is predictable. I concede that it's not clear, even to me, whether Angelika, our bold Lingesh speaker, would thereby also make an assertion the first time she used a plain old phrase not embedded in any sentence. But I don't think it really matters. For suppose her fellow Lingesh speakers follow suit, and many of them

\footnotetext{
${ }^{30}$ I am here in agreement with Cappelen and Lepore (1997).
} 
start using sub-sentences-not, I stress again, sentential structures containing phonologically null elements, but genuine sub-sentences. In such an imagined situation, where the general practice of less-than-sentential speech becomes established, it seems clear, at least to my (admittedly biased) ears, that nothing bars them from making legally binding, "lie-prone", assertions. So, a language without these otherwise unfamiliar empty elements, a simpler language, could be used to make non-sentential assertions. Hence there is no need, at least on grounds of communicative capacity, to posit them.

Before leaving this topic, it's worth stressing just how much hidden material would need to be introduced, so far without independent grounds. For instance, the empty elements will not only appear in the spots Ludlow considers. There will be empty prepositions, empty complementizers, empty negations, etc. And there will be lots and lots of these empty elements. Take Barton's 'An old grudge'. The empty elements in this case would have to contribute the content of 'The White House staff doesn't visit Tip O'Neill in his Congressional office because of _ ' To achieve that, even simplifying greatly, the tree for the thing uttered would be as complex as (25), containing empty I, P, C, and Neg nodes:

(25)

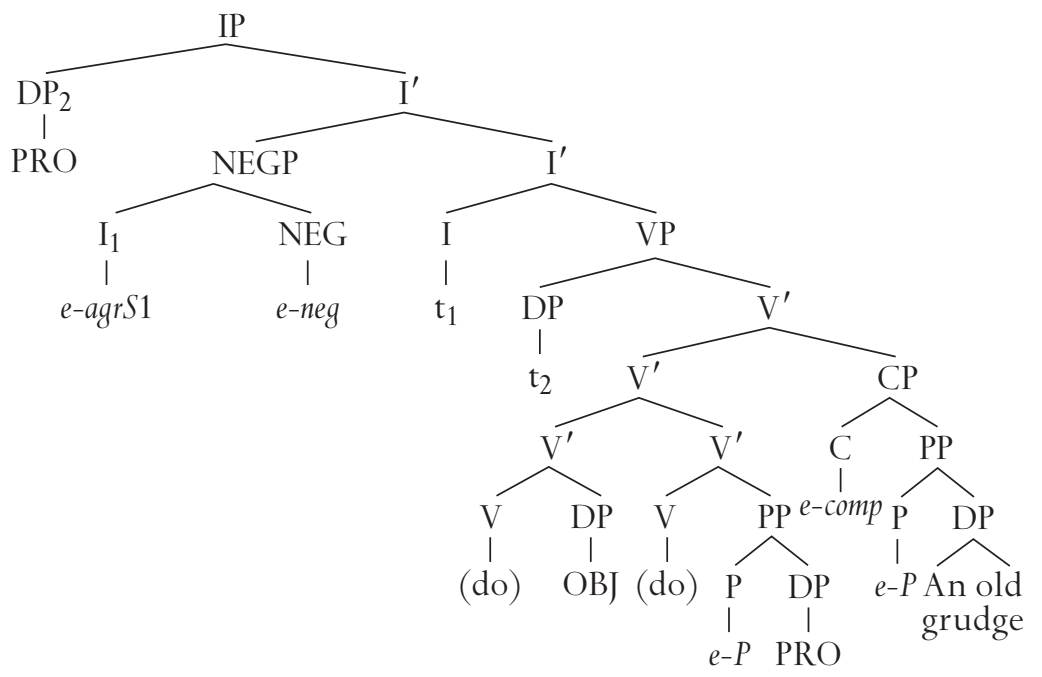

Is it plausible that there is so much hidden structure in this case? And so many different kinds of hidden element?

When considering the answer, notice that no independent evidence has been given for these items, and that it will frequently be indeterminate precisely which sentence-frame is in play. Here is a further example. Suppose that Lucas 


\section{6 / Robert J. Stainton}

is rabidly anti-Brazilian, and he wants to convince his friend that Brazil is the cause of many social ills. Lucas points at two young men, obviously drunk, and says (or appears to say): 'Two bottles of Brazilian gin and vodka'. ${ }^{31}$ Here, Lucas might assert something like what caused those two boys to be so drunk was two bottles of Brazilian gin and vodka. Then again, an equally good paraphrase would be those boys got drunk on two bottles of Brazilian gin and vodka. One could dream up several other sentential paraphrases. On the empty element view, precisely one exceedingly complex sentential structure was used by Lucas. We just don't know yet which one it was. (Similar remarks apply to the 'Chunks of strawberries' and 'Rob's mom' examples, and many others.) Rather than saddle ourselves with a puzzling unknown here, it would be preferable to take the appearances at face value, and grant that the speaker uttered precisely the phrase he appears to have uttered.

Now, these methodological arguments aren't knockdown. But they surely make this second special and technical notion of syntactic ellipsis quite implausible, if no evidence is provided for the empty elements. It thus seems that the only plausible variants of ellipsis, applicable to the cases in question, are ones which recast, rather than reject, a pragmatics-oriented story. Or so one must conclude, barring independent reasons for positing syntactic ellipsis in one of the helpful senses. Which leads to my final topic: recent syntactic arguments for such an ellipsis account.

\section{Ludlow's Challenge: Other Arguments for Syntactic Ellipsis}

Early on in this chapter, I noted two consequences of sub-sentential speech, assuming one takes the appearances at face value: first, that there would be pragmatic determinants of what is said, asserted, or claimed, and second, informational integration, even during speech comprehension, could and would happen in a medium other than spoken language. In Section 3 I contrasted numerous variants on the ellipsis theme, and noted that most of them are unhelpful in avoiding these two consequences. This held both for some commonsense takes on "ellipsis", and for some technical variants as well, e.g. Dalrymple-type accounts. Much of the rest of the chapter has considered

\footnotetext{
31 Notice that this phrase exhibits a scope ambiguity. It is thus extremely implausible that it is not "genuinely linguistic", as Stanley might have it.
} 
whether the two varieties of ellipsis that really would let one reject nonsentential assertion are plausible. The first variant, which sees ellipsis as like the deletion of redundant material in VP ellipsis and sluicing, was found to entail the requirement of a syntactic controller, except in highly marked situations. But syntactic controllers are not at all required for sub-sentence use. The second variant, which sees syntactic ellipsis as a matter of phonologically null elements getting assigned real-world referents from context, was methodologically suspect: it posited lots of hidden structure, whose nature remains largely mysterious, without any explanatory gain at all. Or so I said.

What remains is to make good on this claim that there aren't solid and independent reasons for positing hidden syntactic structure. To do this, I need to address directly some arguments which purport to provide such reasons. That is the task of this section. I will structure my replies around an argument that seems to me to run through Ludlow (2004). The argument, as I reconstruct it, goes like this:

Premise 1. The grammar of English does not generate expressions of the kind required by the pragmatics-oriented approach, except within sentences. Nor does the semantics of English assign meanings to expressions of the kind required, except within sentences.

Premise 2. Apparently sub-sentential speech is grammatical. ${ }^{32}$

Premise 3. If $\mathrm{P} 1$ and $\mathrm{P} 2$ are true, then speakers who appear to utter bare words and phrases must really be uttering sentences.

Conclusion. Speakers who appear to utter bare words and phrases must really be uttering sentences.

Ludlow puts his conclusion this way:

The view that I am defending is that in more cases than not (and perhaps all cases) if we utter something that is well-formed and meaningful then at least at one level of representation [it] is a fully inflected clause. ${ }^{33}$

32 Were it not for this premise, one might say: "It doesn't matter whether the grammar generates words or phrases, since people use ungrammatical expressions all the time to perform speech acts. For instance, non-native speakers frequently make assertions using fractured grammar. Thus the only question is whether words or phrases are used assertorically, not whether they are grammatically so used." Premise 2 is important precisely because it allows Ludlow to block the complaint that grammaticality is irrelevant to the debate at hand.

33 Ludlow (2004: 96). The kind of exception that Ludlow does allow for are cases in which a special code has been pre-established, so that the use of a single word is understood as communicating a full proposition. He gives the example of stipulating beforehand that saying 'apple' means that someone in the crowd has a gun. He rightly sets aside such cases as uninteresting. I gather that these are the only 


\section{8 / Robert J. Stainton}

Ludlow gives a series of examples to support P1. He also offers a more general reason for accepting P1, based on theoretical principles in Chomsky's Minimalist Program. I will discuss these two kinds of argument in turn.

There are surface constructions which have long been considered to be created via transformation. For instance, passive sentences have been thought to work this way. To give an example, and putting things roughly, the idea is that the active voice sentence 'A missile sank that ship' is transformed into 'That ship was sunk by a missile'. Similarly, notes Ludlow, 'The children are all in the garden' is derived by applying a transformation, Q-float, to 'All the children are in the garden'. ${ }^{34}$ Crucially, these sorts of transformations only apply to sentences. Ludlow infers that the grammar does not generate things like the bare phrase 'Sunk by a missile', or the bare phrase 'All in the garden'. It only generates sentences that contain these phrases. Thus P1.

Here is another set of examples, equally designed to support P1. There are morphosyntactic phenomena which are only licensed by specific surrounding syntactic material. One example is case-markings on noun phrases. Case-markings on an NP are taken to require an appropriate expression standing in the right syntactic relation to the NP, such that the case in question gets assigned to the noun phrase by that expression, in that relation. For instance, accusative case is supposed to be assigned by object-agreement features on the verb, where that verb must govern the noun phrase. ${ }^{35}$ Given this, it is reasonable to infer

exceptions he is willing to countenance, and that, in every other case, he will predict that alleged examples of non-sentential speech, where grammatical and meaningful, are in fact uses of structures that are sentential at some level of representation.

${ }^{34}$ It might be thought that a well-known alternative theory of "Q-float", argued for in Sportiche (1988), would pose problems for Ludlow, and thus might support my story. On this view, it is not the quantifier word (e.g. 'all') which floats "down" from the subject position into the VP. Rather, sentential subjects originate inside the VP, and in "Q-float" it is the rest of the complex quantified NP (e.g. 'the children') which moves up from within the VP to subject position, without "pied piping" the quantifier word (e.g. 'all'). Applied to the example at hand, and simplifying, the base form would be [IP__ [VP are all the children in the garden] ], the segment [the children] raises to subject of IP position, and the result becomes [IP the children [VP are all_—in the garden]]. Whatever the merits of this account, however, and whatever complications it poses for Ludlow's positive story, I suspect that it does not especially favor the pragmatics-oriented view any more than more traditional accounts of Q-float. That is because the Sportiche account, like its traditional rivals, equally requires that 'all in the garden' be derived by a sentence-level operation, rather than being base-generated.

35 In Minimalism, case assignment is achieved by "feature checking". The core idea, roughly speaking, is that case-markings on nominals get "checked off" against corresponding features on verbs - though only when the nominal and the verb stand in the right structural relation. Once a case-feature has been "checked", it ceases to be visible at Conceptual Structure. This has the same 
that when accusative case is present, there must be a verb assigning the right sort of agreement features; and that verb must be in the proper syntactic relation to the noun phrase. This kind of phenomenon shows up even more clearly in heavily case-marked languages like German, Russian, and Korean. Importantly for present purposes, that seemingly implies that the grammar of these languages cannot generate bare noun phrases - which are marked for case, yet are completely outside a sentence - for there would then be neither the case-assigning features nor the structural relation in which case gets assigned. Or again, reflexive anaphors like 'himself' must, it seems, be licensed by an appropriate co-indexed NP that stands in the right structural relation (e.g.c-command) to the reflexive. That is why 'Jim's mother likes himself' is ungrammatical: the only appropriate NP is 'Jim', and it does not c-command 'himself'. Again, this seemingly shows that the grammar of English (and of languages generally) cannot generate bare phrases containing reflexive anaphors (e.g. 'From himself'). Instead, the grammar can only generate sentences containing such phrases. Ludlow gives other examples, all of which seem to support P1. But these are sufficient to give the flavor of his first kind of argument. ${ }^{36}$

Insisting that these kinds of phrases cannot be generated outside sentences, Ludlow then observes that phrases of this kind appear to be used in isolation. He infers that the appearances must be misleading: what speakers must really be using, in these cases, are sentences containing unpronounced material. That is how Ludlow's examples support an ellipsis story. (Note too that the syntactic material must be present, in the right structural relationship. It's not just that the content is clear from the "pragmatic" context. So the variety of ellipsis supported is, in fact, the kind that would help the semantics-oriented theorist.)

The second kind of argument that Ludlow offers for P1 is less tied to specific examples. (It also has less of a "retro" flavor.) Before introducing it, it is worth

effect as the old "case filter" of Government and Binding Theory because, crucially, case-marking features are taken to be uninterpretable, and a key principle of Minimalism is that anything still visible at Conceptual Structure must be interpretable. So, if a nominal's case-markings don't get checked - put in GB-talk, if nothing is in the right position to assign case - the case-markings will be both visible and uninterpretable at this interface, and the derivation will "crash".

${ }^{36}$ Some of the examples that Ludlow discusses strike me as beside the point, at least with respect to the present debate. The issue before us, after all, is the semantics-pragmatics boundary, and in particular whether speakers can perform speech acts using things that do not, even in context, encode something propositional. Thus uses of syntactically non-sentential expressions that are nevertheless semantically of type $\left\langle_{e}\right\rangle$ are not in dispute. Hence I put aside as irrelevant Ludlow's examples 'All were' and 'Hood sunk', since I grant that they are "semantically sentential”. 


\section{0 / Robert J. Stainton}

noting why Ludlow needs this broader kind of argument. It is important for his purposes because, without it, the consequent of $\mathrm{P} 3$ would have to read "then speakers who appear to utter bare words and phrases of the kind derived in sentencelevel transformations must really be uttering sentences". At best, as he himself acknowledges, Ludlow's specific examples show only that some speech which looks like the use of sub-sentences might actually be better treated as the use of elliptical sentences. And this is something that believers in genuine nonsentential speech have never denied. ${ }^{37}$ Indeed, I myself have been quite happy to grant this in the past, in part because I do not think it saves the semanticsoriented approach: as long as some cases aren't ellipsis, in the sense required, the pragmatics-oriented approach is vindicated. Realizing this, Ludlow wants to support the stronger view that, some scattered and uninteresting cases of stipulated special uses for bare words aside, all grammatical speech is sentential speech. Towards this end, he describes the fundamental principle behind Chomsky's Minimalist Program as requiring "that grammatical elements must be combined and moved (under economy constraints) until a successful derivation is computed" (Ludlow 2004: 106). In particular, a fundamental principle of Minimalism is the restriction that uninterpretable features must get "erased" ("checked off") before arriving at the end-of-derivation interface: this restriction yields the same effects as the many "filters" in prior frameworks; and, since this checking off sometimes requires that an element move, the demand of full interpretability also yields the same effects as the movement rules of prior frameworks. Ludlow is correct to say that, within Minimalism, the grammar would over-generate wildly if this restriction were removed. Ludlow then suggests that in order for the grammar to generate non-sentences-like 'From Spain', 'Rob's mom', 'An old grudge', and 'Chunks of strawberries' - outside of sentences, this principle would have to be rejected. He writes: "If success could

${ }^{37}$ Indeed, having noted, following Morgan $(1973,1989)$, both that there are "fragments" that appear to arise from sentence-level transformations like tough-movement and passive, and that casemarking in fragments is typically a reflection of the fragments' position in the corresponding full sentence, I myself concluded in an earlier paper that "In my view, such cases strongly suggest that the interpretation of some fragments involves reconstruction of elided material" (Stainton 1997b: 71). Barton (1998) makes a similar concession. That said, as will emerge below, I am now less convinced that these kinds of examples should, on these grounds anyway, be treated as elliptical in the sense required to save the semantics-oriented approach. To anticipate, I now think that whether they are derived via a sentence-level process - which is what Morgan argues for, and what Barton and I concede - is actually neither here nor there, with respect to whether the things uttered are really phrases rather than elliptical sentences. (Compare: that a butterfly passes through a stage in which it is a caterpillar surely does not show that the thing fluttering outside my window actually isn't a butterfly after all.) 
be won for any arbitrary subsentential element, then the theory would be incapable of blocking anything” (Ludlow 2004: 106). Thus, suggests Ludlow, we must either reject Minimalism or we must reject the genuineness of sub-sentential speech.

Interestingly, this broader objection brings together the two parts of P1 above: namely, not being generated by the grammar, and not being assigned a meaning. A central idea underlying the Minimalist Program is that what arrives at the end of a derivation, and remains "visible", must be fully interpretable - if it isn't, the derivation is unsuccessful, and it "crashes". But if no meaning is assigned to bare phrases, then they aren't interpretable; and if they aren't interpretable, then bare phrases can't be left over at the end of a derivation. Hence they cannot be generated by a Minimalist grammar.

Before addressing Ludlow's objections in detail, let me explain why I think that $\mathrm{P} 1$ of my reconstruction, to the effect that the grammar does not generate or assign meanings to words or phrases outside sentences, simply cannot be correct. It is one thing to insist, as Stanley does, that words and phrases are perfectly well-formed but that they cannot be used to perform a genuine speech act, e.g. an assertion. It is quite another to say that words and phrases, if not embedded in a sentence, are just plain ungrammatical, and/or cannot be interpreted at all. A natural reaction to the latter idea is an uncomprehending stare. True, the claim isn't logically incoherent; but it strikes me as up there with the suggestions that all apparent dogs are really robots, or that all sentences underlyingly have the word 'Jehovah' in them. Not to put too fine a point on it, it is immensely implausible that every book title, dictionary entry, label, bank check, etc. is riddled with ungrammaticality and nonsense. Equally implausible is the idea that book titles and such actually aren't phrases, and that trucks, currency, store fronts, and license plates never really have words and phrases on them. This implausibility derives, in part, from the hard-to-fathom consequence that, if these things aren't really words or phrases, then we (whether professional linguists or ordinary folk) don't really know what they are-since we can't (yet) tell what specific sentence underlies the apparent word or phrase. Sometimes this will be because multiple sentences would be equally fine paraphrases. Sometimes it will be because no sentential paraphrase comes to mind at all: for example, when I call out 'Oh Sweet thing' as a vocative, merely to get my spouse's attention, what sentence can I have meant which simply gets her attention, without saying anything about her? Taking another example, I have before me a business card which appears to say 'McMaster University' at the top, followed by the 


\section{2 / Robert J. Stainton}

personal name 'Anita Kothari', affiliations 'Health Research Methodology Program', 'Centre for Health Economics and Policy Analysis', and ending with a street address. But if Ludlow's argument is sound, and only sentences can be used, this business card, assuming its contents are grammatical, cannot really say any of these things. That's peculiar enough. Worse, this business card must contain a slew of sentences whose nature is at the moment outside human ken, in part because no ordinary declarative fits the bill. (Each ordinary sentence would, I take it, incorrectly have the business card containing multiple articulated assertions: "The bearer works at McMaster University", "The bearer is named Anita Kothari”, etc. And, while I grant that the act of handing over the card may convey such things, it seems quite wrong to add that such things are implicitly or covertly contained on the card itself.)

Well, but implausible views are rife in philosophy, and in science too. And some quite implausible theses have proven to be correct. ${ }^{38}$ So, let me move beyond the uncomprehending stare, and raise three problems for P1.

First, and related to the point about not yet knowing what the things are, one can't simply stop with the claim that appearances radically mislead: there is the heavy burden of explaining away street signs, maps, chapter headings, product labels, business cards, names on boats, vocative uses of titles, addressed envelopes, shopping lists, CD covers, dictionary entries, phone books, TV guides, bank checks, book and movie titles, menus, etc. ${ }^{39}$ To cite three specific

\footnotetext{
${ }^{38}$ In fact, Ludlow has been known to reply that this is just another example of a very successful scientific theory conflicting with commonsense appearances, as when chemistry arrived at the surprising conclusion that rusting and burning are very similar processes. I'm willing to let this go, for the sake of argument. But I will say this: I think drawing such a comparison quite seriously misrepresents the present situation. First, as Chomsky (1995) himself regularly insists, inquiry in formal syntax remains in the very beginning stages. Indeed, it is suggestive that he calls his latest attempts a "Program": Minimalism, even more than the Extended Standard Theory or Government and Binding Theory, is genuinely a program of research, just starting to yield its first fruits. What's more, as Chomsky also freely admits, the Minimalist Program can claim far less descriptive adequacy than many of its predecessors. Thus, not to put too fine a point on it, if the Minimalist Program really did have the consequence that every grocery list and business card is either rife with ungrammaticality and nonsense, or covertly filled with undiscoverable sentences, then that really ought to strike one as a quite good reason for rejecting it. (Happily, as I will argue below, I do not think Minimalism entails any such thing.)

39 A great variety of attested cases of (what I would call) sub-sentential speech — produced under a huge array of circumstances, in many linguistic registers and within widely differing media (e.g. everyday conversation, commercial advertisements, recipes, sports commentary, personal ads, literature) - may be found in Wilson (2000). He also offers a useful overview of the scope and range of things sometimes labeled 'ellipsis'.
} 


\section{In Defense of Non-Sentential Assertion / 433}

examples essentially at random, I have before me a water bottle which (appears) to contain:

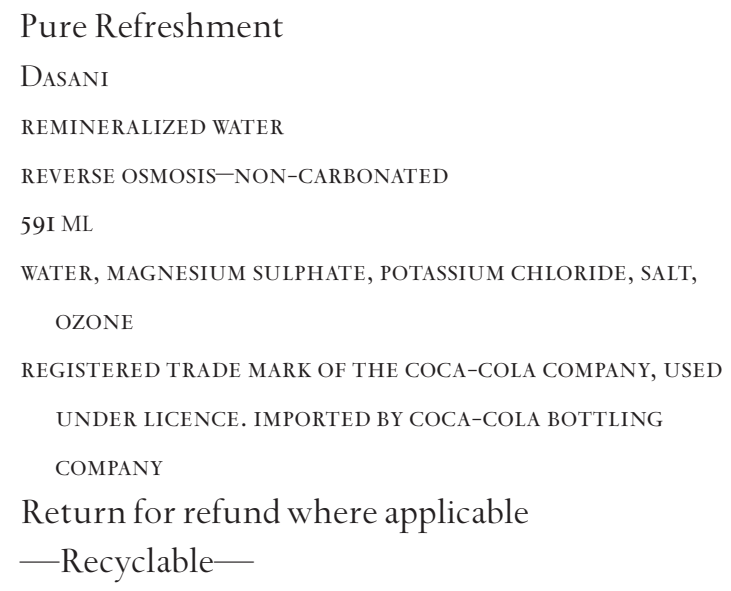

And, on my orange juice bottle I read (or so it seems):

PROVIDES 53\% OF THE RECOMMENDED DAILY INTAKE OF CALCIUM

NEw Minute Maid

I00\% PURF

ORANGE JUICE

FROM CONCENTRATE WITH ADDED CALCIUM

$473 \mathrm{ML}$ CALCIUM RICH

SPECIALLY DESIGNED AS A SOURCE OF CALCIUM FOR PEOPLE WHO

DO NOT DRINK MILK

Finally, opening my Oxford Canadian Dictionary I find (or seem to find):

marrow. n. $1=$ BONE MARROW. 2 the essential part. 3 (in full vegetable marrow) a a large usually white-fleshed gourd used as food. $\mathbf{b}$ the plant, Cucurbita pepo, yielding this.

In all these cases, one seems to find mere words or phrases being used grammatically, and with a genuine content. If Ludlow is right, however, these and other cases must be explained away as mere appearance: either each apparent word or phrase on the bottles and in the dictionary must be ungrammatical and/or contentless, or each must be underlyingly sentential. The problem is, absolutely none of this explaining away has yet been done.

Second, notice that there are two kinds of appearances being denied. The first is that our linguistic competence generates words or phrases, so that these very things can get regularly used in grammatical speech. That we are misled about 


\section{4 / Robert J. Stainton}

this is easier to swallow: our supposed "error" here might be explained by some kind of performance error, and by the general point that people have a quite shaky grasp on their own competence. But the second kind of appearance we have to deny is about what we do with these expressions. It has to do with errors about our own performance, not merely about our competence. Specifically, we think we often mean something sub-propositional when we produce what appears to be a word or phrase. However, if all such things are underlyingly sentential, and if what determines speech act content is just disambiguation and slot-filling (as per the view being defended), we are presumably regularly wrong about what speech acts we perform in using these items. We are asserting, though we think we are only vocatively calling out a name or title. We are asserting, though we think we are only labeling. And so on. (There is, of course, an implicit assumption behind my present critique: that if pragmatic enrichment can't add content or force to a speech act proper, then it can't take content or force away either. Crudely, if pragmatics won't let you assert with a referring or predicative expression, it equally won't let you refer with an assertoric expression.) To put the point in terms of causes and effects, one can think of linguistic competence as one causal force among others, giving rise to the effect of performance. For instance, grammaticality is one causal factor that contributes to the effect of whether a sentence "sounds right"; but grammaticality is not the only factor, since memory limitations and so forth contribute to the observed effect as well. It's then natural to say that ordinary people are often wrong about the causes: they find that a sentence doesn't "sound right", and they incorrectly conclude that ungrammaticality, a matter of the linguistic competence, is the cause. Thus is speaker error explained away. The problem, put in terms of cause and effect, is that Ludlow appears committed not only to our being wrong about the causes of what appears to be sub-sentence use, but also to our being very frequently wrong about the effect of such speech. We think the effect is to label, or draw attention, but we are mistaken: in fact, we must have asserted.

Putting aside our ordinary talk exchanges, there is a more artificial situation which seems to demonstrate our competence with bare words or phrases. This third problem for P1 has to do with native speakers' contrastive judgments about bare words and phrases, in response to investigator queries. With respect to the "content" side of P1, if we ask a reliable subject whether 'Big cats and dogs' is ambiguous - without offering up any sort of sentence-frame, or any discourse context - they can (rightly) say that it is. The same holds for the bare word 'can': ordinary folks seemingly know that it, the word, is ambiguous. Or again, turning to the "grammatical" side of P1, if we ask a reliable subject 
whether 'The if second at' is just as grammatical as 'The man who lives next door' - again, without offering any sentential frame or context whatever - she can easily report that it is not. This presumably should not be possible, if the grammar does not generate phrases outside sentences, and does not assign a meaning to them. To come at basically the same point another way, one can give a group of subjects a piece of paper with bare words and phrases on the left, and corresponding drawings on the right, and indicate by example that one is to connect the words phrases with the corresponding picture. Having tried this out, let me report the wholly unsurprising result that people can do this task without the least difficulty. Let me add, too, that informants can make judgments, and perform tasks, that require knowledge of the content and syntactic form of 'all in the garden', 'sunk by a missile', and 'from himself'. Someone who endorses P1 needs to find a way to explain how this is possible, despite the fact that the subjects' competence says nothing whatever about words phrases outside sentences.

In sum, whatever Ludlow's two kinds of argument show, I believe they simply cannot show that English words and phrases are all (or mostly all) both ungrammatical and gibberish, unless embedded in a sentence. Since P1 can't be right, and his arguments seem to support it, it behoves me to explain where his arguments in support of $\mathrm{P} 1 \mathrm{might}$ have gone wrong. I'll begin with his specific difficult cases, and then turn to the broader point about Minimalism.

In discussing constructions such as passive, it is important to distinguish whether the grammar generates something, from how the grammar generates it. Ludlow claims, for example, that passive phrases such as 'sunk by a missile' are created by sentence-level processes. Similarly for Q-float phrases like 'all in the garden'. But, I want to ask, even if true, how exactly would this show that 'sunk by a missile' and 'all in the garden' are not generated at all, except within sentences? At best the argument would demonstrate that in deriving such phrases, the derivation must pass through some stage at which the phrase is embedded in a sentence-frame. But even if that were true, crucially, the result of such a process would still be the plain old phrase. It would not be a sentence. Thus even if the derivation worked like that, it would still be the case that speakers were producing words or phrases, not sentences. ${ }^{40}$ This offers one means of resisting

\footnotetext{
${ }^{40}$ It is worth mentioning here another kind of case that Ludlow (2004) considers. He notes that there are idiom chunks that must occur in the presence of a special verb, giving the example of 'close tabs'. This idiom chunk must be generated with the verb 'keep', in the right structural relation. (To 'keep close tabs on something', for those who don't know the dialect, means to monitor that something closely.) Given this, it once again seems that the grammar cannot generate the bare
} 


\section{6 / Robert J. Stainton}

P1 — which, Iinsist, just cannot be right - while taking into account some of the examples which Ludlow provides. ${ }^{41}$

Of course another possibility for the generation of unembedded phrases exhibiting passive and Q-float is that these sort of phrases are not created by a transformation at all, but are instead base-generated. Given the decreasing importance of surface-level transformations nowadays, and given how underdeveloped the alternative Minimalist Program remains with respect to specific constructions like these, this could very well be what is going on. Either way, it's early days to conclude that, extremely implausible as it may seem, such expressions simply cannot be generated at all.

The argument from licensing, applied above to both case and reflexive anaphors, is different from the argument from sentence-level processes. In the latter sort of examples, the licensing material has to be present not just at some stage, but always. Hence the reply "It's not how, it's whether they're generated" will not work for these examples. Some other explanation must be given of how, though these examples seem to entail P1, they don't really do so. I will address case and reflexives in turn.

With respect to case, the most obvious view is that espoused by Barton and Progovac (2004), who write that "nonsententials differ from sententials in one basic property: they are not required to check Case features" (p. 85). One might wonder, of course, why there is this difference. A natural answer goes like this. Many languages have a default, or unmarked, case. A simple example is provided by contrasting unembedded personal pronouns in English and Spanish. In English one puts up a hand and says 'Me, me', in accusative. In Spanish one uses not accusative but nominative: one puts up a hand and says 'I, I'. This illustrates

expression 'close tabs'. It can only generate sentences containing this expression together with 'keep'. So, argues Ludlow, when it appears that people utter 'Close tabs!' unembedded, they really must be uttering a sentence. In response, I would apply the same reasoning offered in the text: it may be that the "how" of 'close tabs' being generated will involve a sentential frame (including 'keep'); but it doesn't follow that this phrase is neither grammatical nor contentful outside the context of a sentence. So idiom chunks don't support P1 after all.

${ }^{41}$ Morgan (1989: 240) makes a similar point, contrasting (a) fragments being generated derivatively of sentences with $(b)$ individual spoken fragments being derived from sentences. Spelling out this idea, Morgan notes that we could make a technical refinement to the notion of 'generates'such that " $\mathrm{G}$ generates a string $\mathrm{X}$, with structural description $\mathrm{SD}$, just in case $\mathrm{X}$ is analyzable as SD in the surface structure of some S generated by G" (Morgan 1989: 230). This would then make it the case that idiom chunks, case-marked phrases, passivized phrases, etc., are all generated because the grammar generates sentences containing them. Yet it would not be the case that the speaker of such an item, in isolation, had "really" uttered a sentence. Rather, they uttered a mere phrase - which phrase is licensed by the grammar in virtue of its being a constituent of some sentence(s). 
their different default (unmarked) cases. Spelling out Barton and Progovac's idea, it is reasonable to add that no licensor is required for unembedded phrases exhibiting the default case, whatever it happens to be. Put in Minimalist terms, default case does not need to get "checked" on non-sententials. (Maybe that's what it means to call it "default".) An external licensor is also not required for N-bar fragments, like 'Nice car' and 'Flat tire', because these occur not as arguments, but as predicates. ${ }^{42}$ So, this captures two instances where case doesn't get checked. There is a third rather different kind of example, however: there are certain examples where non-default case shows up on an NP that is functioning as the "argument" with respect to the proposition asserted. Here, though, the case-marking plays a semantic role, e.g. when the presence of nominative versus accusative indicates whether the denotation of the NP is agent, patient, etc. In this circumstance, case doesn't need to get checked because it is interpretableand in Minimalism, what is interpretable can remain visible at Conceptual Structure. Applying this to an example, we see why a German speaker will identify a substance with 'Ein Kaffee' [Nom] in isolation, while she will request the same substance with 'Einen Kaffee' $[$ ACC] in isolation. The former exhibits nominative marking because that is the default case in German, while the latter exhibits the accusative marking because of the content of the speech act. Thus case is allowed to be visible in this special circumstance, because the case-markings are getting interpreted at Conceptual Structure.

An alternative sententialist story, of course, is that a case-bearing "fragment" is derived, by deletion say, from a sentential source - this hypothesis being supported on the grounds that the case of the fragment always reflects the case which the phrase exhibits in the corresponding sentence. This is frequently taken as evidence that ellipsis is taking place. Morgan (1989: 232), for example, notes the following contrast in Korean. Where the questions at issue is "Who did you see?", the accusative-marked name (26) is well-formed as an assertion, but the nominative-marked name (27) is not. In contrast, when the question at

42 Barton and Progovac (2004) treat these cases somewhat differently. They adopt Abney's (1987) DP hypothesis, treating these sort of expressions not as N-bars, but rather as NPs that do not project to DP. They then suggest that it is the presence of D which demands case-checking. Not being DPs, hence lacking D, these examples thus do not need to undergo case-checking. As they note, this explains why 'Car broken down' is fine, as a way of communicating that the car is broken down, whereas 'The car broken down' is bad. 'The car broken down' cannot be so used because 'the car' here is a DP functioning as an argument, hence it would need to have its case features checked. (Of course 'The car broken down' can be used, e.g. when pointing at a picture of the car in its unfortunate state; but this usage is not predicating BROKEN DOWN of the argument THE CAR.) 


\section{8 / Robert J. Stainton}

issue is "Who bought this book?", just the reverse is true: the answering phrase must be marked nominative, as in (27), not accusative, as in (26).
(26) Yongsu-ka
Yongsu (acc.)
(27) Yongsu-rul
Yongsu (nom.).

A natural explanation for this pattern is that what the speaker must utter, to convey the answer "Yongsu" to the question "Who did you see?", is (underlyingly) the sentence (28). And this sentential structure demands accusative marking on the name. In contrast, what the speaker must utter, in conveying the answer "Yongsu" to the question "Who bought this book?", is (underlyingly) the sentence (29). This sentence demands nominative on the name.
(28) Yongsu-rul po-ass-ta
Yongsu (acc.) saw
"I saw Yongsu"
(29) Yongsu-ka sa-ass-ta
Yongsu (nom.) bought
"Yongsu bought it"

But this deletion-based story ought to be rejected, at least as a general account, because it simplifies matters far too much. For instance, suppose Hans and Frank are speaking German, discussing things which reminds them of various people. They part, and meet up again a few days later. The first thing Hans says, in German, is 'My father', pointing at an old beer-stained table. The corresponding sentence would have to be (30), with 'my' in accusative. (The context 'reminds me of ___ demands this case in German.) But the sub-sentence that one uses in this scenario, in German, actually exhibits the nominative case, as in (31). ${ }^{43}$

$$
\begin{aligned}
& \text { (30) Das erinnert mich an meinen Vater } \\
& \text { That reminds me of my-ACC father } \\
& \text { (31) Mein Vater } \\
& \text { My-Nom father. }
\end{aligned}
$$

In this example, then, it is simply not true that the Case of the phrase in isolation corresponds to what it would have been in a sentence. The ellipsis story

\footnotetext{
${ }^{43}$ I am indebted to Corinne Iten for the example, and for discussion of the German facts.
} 
makes the wrong prediction. (Notice, in contrast, that the positive non-sententialist account of case, sketched above, applies straightforwardly: the phrase takes on nominative case, the default, because using accusative case would carry the (unwanted) semantic information that the denotation was the theme (patient).) Nor is German the only language where case markings ultimately point away from an ellipsis analysis. Thus Morgan (1989: 236-8) himself notes that Korean has both case-marked noun forms and case-less forms, each apparently occurring unembedded. ${ }^{44}$ Morgan argues that the case-marked forms are derived from sentences, but that the case-less forms are not: they are bare phrases, even generated as such, which may be used to make assertions and other speech acts. This must be the case because, when embedded in a sentence, they are ill-formed. Consider, finally, the case of pronouns in English. If ellipsis were occurring, one would expect the case of the pronoun to be that which shows up in the corresponding sentence. But, in many situations, even though the isolated English pronoun is marked accusative, the case on the corresponding embedded pronoun must be nominative. Recall, for example, how in English one puts up a hand and says 'Me, me' not 'I, I'. Spelling out the example, if the question in the air has to do with who likes Elvis best, the fans will shout 'Me, me!', even though the corresponding sentence would be 'I like Elvis best!' So again, the ellipsis story makes the wrong prediction about what case will show up on the unembedded phrase.

Given that an alternative story can explain the facts, while allowing words and phrases to be generated, and given that certain examples in English, German, and Korean actually cut against the case-is-only-licensed-within-sentences story, we should conclude that appeals to case-marking do not come close to establishing P1 after all. Which is just as well, as I've said, since P1, though logically possible, is wildly implausible.

Ludlow also argued, as noted above, that English grammar cannot freely generate anaphor-containing phrases outside of sentences, because anaphors require a c-commanding antecedent. This again suggests that what speakers really utter, when they seem to utter bare anaphor-containing phrases, aren't really bare phrases after all. For example, Alex could look through Betty's photo

\footnotetext{
${ }^{44}$ Interestingly, the Korean case-less forms require no linguistic context, though they are also permitted to occur within a discourse context; in contrast, the case-marked forms require overt linguistic context, e.g. a question asked. To give an example from Morgan, 'nae cha!' "my car" (no case)] can be used by a person returning to a parking lot and finding her car stolen. But both "nae cha-ka' ["my car" (nom.)] and "nae cha-rul' ["my car" (acc.)] are ill-formed in that discourse initial circumstance.
} 


\section{0 / Robert J. Stainton}

album, and finding a picture of Betty on nearly every page, he could turn the page once more and (appear to) say:

(32) Another picture of herself!

On Ludlow's view, what Alex really must have produced is a complete sentence that contains the phrase 'another picture of herself' as a proper part. Otherwise, Alex's ability to speak this way would falsify Principle A of the Binding Theory, since we would here have the grammatical appearance of an anaphor without a c-commanding antecedent.

In reply, I think one must simply conclude that it is not universally true that reflexive anaphors must be licensed by a c-commanding co-indexed NP. But this conclusion is not really that hard to accept. First, there are independent reasons having nothing to do with sub-sentential speech for thinking that there are "exempt anaphors" that are not subject to Binding Theory's Condition A, as the latter is classically construed. Indeed, "picture noun reflexives" like the one in (32) are among the most familiar candidates for being exempt. Building on work by Postal (1971), Kuno (1987), and Zribi-Hertz (1989) among others, Pollard and Sag (1992) argue that exempt anaphors may be licensed by "discourse", in the broad sense of point of view and content, rather than being licensed by a c-commanding syntactic item which is a co-argument. So the appearance of unbound reflexive anaphors is not something peculiar to subsentential speech. ${ }^{45}$ Indeed, to drive home the point that (apparently) unbound reflexive pronouns do not per se point towards an ellipsis analysis, note that the complete sentence 'Here's yet another picture of herself!', which lacks an antecedent for the reflexive is fine-and surely it isn't elliptical for anything. Second, as noted in Stainton (1993), such reflexives can occur without any prior discourse whatever. (I would now add, in light of Stanley's criticisms, that they can occur with no eyebrow raisings, etc., either.) Given this, at least some

\footnotetext{
45 Nor are these the only kind of exception. Reinhart and Reuland (1993 and elsewhere) discuss examples like 'There were five tourists in the room apart from myself' and 'She gave both Brenda and myself a dirty look'. In neither case is the reflexive pronoun 'myself' c-commanded by an antecedent NP. As Reinhart and Reuland point out, however, in these and related cases there is not a "reflexive-marked predicate" in play-i.e. there is no predicate with the same argument appearing twice. Since they further contend that Condition A, properly construed, is actually about reflexivization in this sense, rather than being about co-indexing under a structural relation (e.g. c-command) per se, such cases are not, in their view, ultimately violations of (their variant on) Condition A. That, they maintain, is why these sentences are well-formed, despite the lack of a c-commanding antecedent for the reflexive pronoun. For further complications, see Keller and Asudeh (2001).
} 
theories of ellipsis will have to say that these cases are not elliptical, in the sense required to preserve the semantics-oriented approach. Also, there are expressions which are clearly not elliptical sentences, but which may contain reflexives, and without a syntactic antecedent. I have in mind 'ditto'-phrases. Thus Luke may non-linguistically convey that the barber shaves Bill, and John may reply:

(33) Ditto for himself.

Since there is evidently no sentence that (33) could be elliptical for, this provides another, independent, case of 'himself' occurring without a syntactic binder.

Having rebutted a number of specific examples that Ludlow offers, which initially seemed to support P1, let me briefly turn to his broader objection. Ludlow worries that a Minimalist grammar would over-generate massively if sub-sentences could be derived without "crashing”. But, frankly, I do not see why Minimalism is, or needs to be, committed to having only IPs interface with Conceptual Structure. Indeed, as Barton and Progovac (2004) point out, it seems rather that Minimalism in particular should not be committed to a special status for sentences. They write:

Since both phrases and clauses are derived bottom-up through merger, to say that generation must start with a sentence would be problematic in [the Minimalist] framework for two reasons. First, it would be contrary to the minimalist considerations of structure building. Second, it would be pure stipulation, given that there is nothing special about sentence/clause in this framework. (2004: 74)

[The generation of non-IPs] via merger is supported and reinforced within the framework of Minimalism by two of its basic properties: (i) the bottom-up strategy of phrase creation based on merger of words, rather than a top-down strategy which would start with an arbitrary top category, such as sentence; and (ii) by the general requirement in Minimalism for economy, which prohibits any superfluous and unmotivated pieces of structure. (2004: 75)

Nor, pace Ludlow, is it the case that generating non-IPs would leave no constraints at all: the key constraint remains that any material which has not been "checked" has to be interpretable by the Conceptual System. (This general constraint would explain, as noted, why non-default case-markings are allowed on sub-sentential utterances when, but only when, case has a semantic role to play - e.g. indicating whether the item mentioned is agent, theme, or whathave-you. As explained above, case doesn't get checked off in such cases, but that's acceptable because case here actually gets interpreted.) So, Minimalism does not need to privilege IPs. 


\section{2 / Robert J. Stainton}

Unless, of course, only IPs are interpretable. If nothing else can be interpreted, then nothing else can be allowed to arrive at Conceptual Structure without crashing. Thus the key issue remains the one flagged above: within Minimalism, sub-sentences can be allowed to be generated only if they are interpretable. But, since we surely can interpret words or phrases without any linguistic or other context - noticing their entailment patterns, ambiguities, anomalies, etc.then surely they are interpretable. (To claim this is not, let me stress again, immediately to make the stronger claim that they can be used to perform speech acts. I hold that too, but that claim needs defending in a way that the bare interpretability of words or phrases does not.) Given that such things can be interpreted, there is, pace Ludlow, no reason to think that Minimalism rules them out.

Once we grant that words or phrases are generated, and assigned a meaningi.e. once we reject $\mathrm{P} 1$ - there remains no positive reason, from Minimalism or elsewhere, for thinking that syntactic ellipsis is going on in such cases. I have also argued that the specific examples which Ludlow gives, which seem to support P1, do not actually do so. Given this, the central criticism of the empty element view is sustained: there is simply no need to posit an unfamiliar kind of syntactic ellipsis here, since pragmatics is required anyway, and can easily enough fill the gap.

\section{Concluding Remarks on Implications (and Genuineness Again): Six Theses}

My defense of non-sentential assertion is now complete. Before moving on to implications, let me very briefly review the results of that complex defense.

I responded to Stanley in three ways: I set aside "shorthand" as underdescribed; I argued that, pace Stanley, sub-sentential speech often achieves the level of a genuine speech act, the key point here being the deep formal, functional, and informational similarities between sub-sentential speech and fully sentential speech; and, having canvassed in Section 3 several things one might mean by "ellipsis", I argued that the only two variants of "ellipsis" that are at all worked out, and that would really avoid the consequences Stanley wishes to avoid - i.e. the Sag-style deletion variant and the Ludlow-style empty element variant — cannot plausibly be applied to sub-sentential speech in very, very many cases. Thus, once "shorthand" is set aside, there are a host of examples of (apparently) sub-sentential speech that $(a)$ cannot be reduced to any familiar 
(and helpful) notion of "ellipsis" and yet (b) clearly are genuine speech acts. Hence Stanley's “divide and conquer” strategy will not cover all cases.

I responded to Ludlow by making four key points. First, it just cannot be true that our competence assigns an asterisk equally to all unembedded subsentential expressions, and that it assigns no meaning whatever to them. It is somewhat controversial that speakers can use bare words and phrases to perform speech acts; but it stretches credulity too far to maintain that words and phrases are simply never understood or used grammatically. Second, it's crucial to distinguish whether non-sentences are generated from how they are generated. It might be that (some) non-sentences - e.g. passivized phrases, idiom chunks, etc.- - are derived by a process that involves embedding them in a sentenceframe at some stage. But, even if true, this wouldn't show that such bare phrases aren't really generated at all, so that the only thing one can use are sentences. Third, it's not at all clear that Minimalism is in conflict with the existence of bare words and phrases. To the contrary, some authors have argued that Minimalism predicts their existence straightforwardly. (However, if Minimalism is in conflict with the production and comprehension of bare words and phrases, the right conclusion is surely "So much the worse for Minimalism" — since, to repeat, it's patent that words and phrases are used on business cards, street signs, maps, etc.) And if Minimalism is consistent with words or phrases being generated, it is presumably also consistent with them being used assertorically, on the grounds that Minimalist syntax simply makes no commitments one way or the other vis-à-vis what speech acts can be made with things generated by the grammar. Finally, I considered two constructions that seemed particularly worrisome: phrases that bear case and phrases that contain reflexive anaphors. I argued that the facts about case are actually more complicated than a syntactic ellipsis account allows (recall the German and Korean data), and proposed that case might be appearing on bare phrases in some instances as a bearer of information about thematic role and such, in other instances as default. With respect to reflexive anaphors, I gave reasons independent of non-sentential speech for thinking that they actually can occur without a c-commanding binder.

I want to end the chapter by returning to the implications of non-sentential assertion. Such implications are important in their own right, of course. But considering the implications carefully is also important because if certain things aren't implied by the reality of non-sentential assertion, it can be easier to accept the genuineness of the phenomenon. The game plan for this final section is as follows. First, I rehearse six theses, four of which have appeared above - though 


\section{4 / Robert J. Stainton}

not necessarily in so many words - and two of which make their first appearance below. The theses in question are:

(T1) Truth-conditional semantics is justified.

(T2) Truth-conditional interpretation is fundamentally different from other kinds of interpretation (e.g. the kind involved in interpreting kicks under the table and taps on the shoulder).

(T3) All truth-conditional effects of context are traceable to logical form. Put otherwise, all truth-conditional context dependence results from fixing the values of contextually sensitive elements in the real structure of natural language sentences.

(T4) All effects of extra-linguistic context on the truth conditions of an assertion are traceable to logical form.

(T5) There are no genuine examples of non-sentential assertions.

(T6) All apparent cases of non-sentential assertions are merely apparent, falling into one of three categories: they are either $(a)$ not genuine linguistic acts, (b) not genuinely sub-sentential, because (plausibly) syntactically elliptical, or (c) shorthand.

Second I revisit how the four familiar theses relate to one another. This initial discussion will serve to highlight again some of the previously discussed implications of non-sentential assertion: in particular, I hope to clarify still further the sense in which the pair T3-T4 entails the pair T5-T6. That's the bit about "implications which are important in their own right". In addition, I consider the relationship between the two theses that have not been discussed explicitly until now (T1-T2) and the other four. What will emerge, among other things, is that the pair T1-T2 does not entail T5. Indeed, I think one can endorse T1-T2 and reject all of the other theses. That's the bit about "if certain things aren't implied, it can be easier to accept the genuineness of the phenomenon".

Let me begin with what the theses say. Thesis T1 endorses semantics built around truth-conditions. There are various flavors of truth conditional semantics, of course. There is truth-theoretic semantics, as pursued by Tarski, Davidson, and their followers. There is truth-centered semantics of the Fregean variety, which has the meaning of a sentence going together with how the world is, to determine a truth value as referent. There is the possible worlds variation on the latter. And so on. T1 is meant to be silent on which variety is correct: it says only that the general approach is on the right track.

Thesis $\mathrm{T} 2$ rejects the idea that all interpretation is of a piece. In particular, interpreting language, which is truth-conditional interpretation, is special and 
different. Differences that come immediately to mind are: that linguistic interpretation is compositional and recursive; that a special encapsulated knowledge base is at play; that such interpretation is algorithmic rather than abductive; and so on. Some will add, as motivation for T2, that linguistic interpretation being different is crucial to the ultimate success of truth-conditional semantics, since the kind of interpretation at work in figuring out why so-and-so kicked me might appear intractable, especially using the kinds of formal means at the disposal of formal semanticists. Thus T1 may well bring T2 in its wake, in some loose sense, because for truth-conditional semantics to be tractable-hence "justified" - there must be a part of linguistic interpretation that is distinctive, thereby making it more tractable than the understanding of kicks and taps.

Thesis T4 showed up early on, in the form of the issue of pragmatic determinants of what is asserted, stated, or claimed: cases in which "pragmatic processes" (e.g. general-purpose inference, on the basis of all available information) supposedly play a role in the determination of what is asserted. (Well, more precisely, such processes play this role in a way that goes beyond disambiguation and "slotfilling”.) As explained at the outset, the view that truth conditions are affected by pragmatics in this additional way - a view defended by Robyn Carston (1988), François Recanati (1989), Dan Sperber and Deirdre Wilson (1986), and Charles Travis (1985) among others - contrasts with the purportedly Gricean (1975) idea that what is asserted is exhaustively determined by disambiguation and reference assignment to explicitly indexical elements. That is, as many people read Grice, it is only "what the speaker meant", and not "what the speaker literally stated", that is calculated pragmatically. To take one example, Recanati (1989) believes that what is strictly and literally asserted by an utterance of 'I've had breakfast', in reply to the question whether one is hungry, can be that the speaker has had breakfast on the day in question. (The speaker may also thereby implicates that she is not hungry. But that's another matter.) According to this view, the speaker would not, in this instance, simply assert that at some time in his life he had eaten breakfast, while merely communicating that he had eaten breakfast on the day of the speaking. That is, this latter proposition is not just implicated, it is "said" ${ }^{46}$ On the other hand, arriving at this proposition requires

\footnotetext{
46 As noted above, Kent Bach (1994a and elsewhere) has argued that one should restrict the term 'what is said' to the result of disambiguation and reference assignment. Thus "what is said" by a nonsentential utterance, in Bach's minimal sense, is not a proposition. He also insists, however, that "what is said" in his sense falls quite far short of what is asserted, asked, or demanded. (Thus on his view, "what is said" by an utterance of 'I've had breakfast' is precisely that the speaker has, at some time in his life, eaten breakfast. Bach would add, however, that this is not necessarily what is asserted.) As I have
} 


\section{6 / Robert J. Stainton}

appeal to salient real-world information - for instance, the information that eating breakfast is an exceedingly common practice, so that it's very unlikely that the speaker would never have eaten breakfast in his life, and hence quite unlikely that he is communicating the obvious proposition that he has done so. (Compare, 'I've had lizard'.) So "what is said" in this case is partially determined by information provided only pragmatically.

As for thesis T3, it encompasses not only assertion, but speech acts generally. T3 requires that the truth-conditional effects on all speech acts-questions, promises, commands, and so forth - be traceable to items in logical form: if there are pragmatic determinants of what is asked or commanded or promised (again, that go beyond some role in "slot-filling" and disambiguation), T3 is false.

T5 baldly denies the genuineness of non-sentential assertions. Not much need be said to explain it. T6 makes good on the claim that speakers only appear to perform non-sentential assertion, by drawing on Stanley's "divide and conquer" maneuver. Having discussed these issues at great length, I won't say more about them right here.

So much for what the six theses say. Let me turn, first, to how the latter four theses relate. $\mathrm{P} 4$ is a special case of $\mathrm{P} 3$ : $\mathrm{P} 3$ says that there are no pragmatic determinants of truth conditions at all; $\mathrm{P} 4$ says that there aren't any in the special case of assertion. Instead, what determines truth conditions is just disambiguated logical form, plus reference assigned to any indexicals. (Notice, by the way, that $\mathrm{T} 3$ could still be false, even if T4 is true - if there are pragmatic determinants of what is promised, or asked, or commanded.) T5, in essence, is forced upon one by T4: if there are no pragmatic determinants of what is asserted, then there can't be any in the particular case of sub-sentential speech. Returning to the earlier example, it seems that the hearer of 'From Spain' must consult the extralinguistic context to find the thing which the speaker who utters 'From Spain' most likely had in mind. (Here, the displayed letter.) This is a role for context which is not built into the logical form of the expression used - though there is, of course, a sense in which the sub-propositional content of the expression helps along the relevance-driven search for something to "saturate" the property, so as to yield a proposition-meant. Since sub-sentence use seems to provide counterexamples to T4, the only way to save T4 is if non-sentential assertions are not genuine: they either aren't genuinely assertions, or they aren't genuinely sub-sentential. Thus T5. The problem is, simply asserting T5 seems to fly in the

suggested, given his usage of 'what is said', I do not think there is ultimately much substantive disagreement between my view and his, since Bach will not deny that there are sub-sentential, albeit fully propositional, assertions. 
face of experience. To make T5 plausible, these appearances must be explained away. That is the job of T6: to explain away every apparent example by assigning it to one of three categories. (Notice that Ludlow's arguments come in precisely here, since they seem to provide further reasons for favoring a syntactic ellipsis account in many cases.) So we have:

(T3) (no pragmatic determinants of truth conditions) $\rightarrow$ (T4) (no pragmatic determinants of what is asserted).

(T4) (no pragmatic determinants of what is asserted) $\rightarrow$ T5 (no genuine non-sentential assertions).

(T5) (no genuine non-sentential assertions) $\rightarrow$ (T6) (all apparent cases fall into three categories).

I should stress that the arrows above need not amount to "logically entails". Since T4 is a special case of T3, it's arguable that there is genuine entailment here. But T4 requires T5 in the sense that the latter sets aside one variety of purported counterexample as not genuine. And T5 requires T6 only in the sense that T6 affords one way to explain away the appearances that initially make T5 look implausible.

Two notes are in order about further relations between these four. First, I pointed out above that $\mathrm{T} 3$ can be false because of pragmatic determinants of what is promised, or asked, or what-have-you. In particular, let me now add, T3 could be falsified by sub-sentential promises, questions, or orders. So non-sentence use remains apposite to T3 even if T5 is true. Second, and to anticipate a point that will re-emerge at the very end, it's worth stressing how T5 might be used to support T4 (the thesis about assertion) and T3 (the more general claim). T5 plays this supporting role in the sense that if there isn't any good evidence for pragmatic effects on truth conditions, then it might (I stress: might) be safe to assume, as the simplest hypothesis, that the only effects on truth conditions come from $(a)$ the structure of the expression and $(b)$ the denotations of the elements of that structure - some of these denotations being extra-linguistically determined, via the appearance of indexicals. The idea here is that the burden of proof may rest with those who would deny T4 and T3: they need to provide counterexamples. Thus, Stanley and Ludlow both try to argue that all the alleged counterexamples from non-sentence use are unconvincing. Therefore, T3 and T4 are sustained, in so far as they are the default assumptions. (Whether this move from the truth of T5 to the truth of T3-T4 is actually warranted is, of course, a more complex matter. Elugardo and Stainton $2004 b$ address such "burden of proof" issues at some length.) 


\section{8 / Robert J. Stainton}

Now that the six theses have been explained, and the relations between the latter four of them have been noted, we can turn to the question of how the pair $\mathrm{T} 1-\mathrm{T} 2$ relate to $\mathrm{T} 3 \mathrm{et}$ al. If all truth-conditional effects of context are traceable to logical form, then there is a very clear difference between natural language communication and other sorts of communicative behavior: specifically, natural language utterances have their (literal) content determined solely by semantic operations on their logical forms, where those logical forms can at most be context-dependent in the sense of containing explicit "slots" to be filled in. In short, T3 supports T2. (As does T4, for the special case of assertion.) T3 also supports T1, because the former thesis establishes a tight connection between something patently linguistic (i.e. logical form) and truth conditions, which, in turn, makes it plausible that one will be able to generate truth conditions for linguistic expressions - as justifying truth-conditional semantics requires. Specifically, truth-conditional semantics can remain, as always, the theory of how the truth conditions of whole sentences get compositionally determined from the structure of the expression (i.e. its logical form) plus the meaning assignments of its parts - where some of those parts have constant meanings, and some of them (i.e. the indexicals) have their meaning fixed by context.

In short:

(T3) (no pragmatic determinants of truth conditions) $\rightarrow$ (T1) (truthconditional semantics is justified).

(T3) (no pragmatic determinants of truth conditions) $\rightarrow$ (T2) (truth conditional interpretation is different).

What remains to consider is how T1-T2 relate to T5-T6. I'll get to that very shortly. But first, having them laid out this way, let me now clarify even more explicitly my own views on the last four theses. I have argued, here and elsewhere, that T6 isn't true. But then there are lots of non-sentential assertions which cannot be explained away. I can thus run several iterations of modus tollens on the argument from the previous page, concluding first that T5 isn't true because T6 isn't; concluding further that since non-sentential assertion is a genuine phenomenon, and not merely apparent, this means that neither of T4 or T3 is true either: neither of them is consistent with the existence of nonsentential assertions. So, there are pragmatic determinants of what is asserted in particular, and of speech act content in general. And informational integration, even during speech understanding, presumably is not, then, a matter of building up linguistic structures and assigning extra-linguistic referents to those natural language structures. I also believe, though I have not argued the 
point here, that even if T5 is true, so that there aren't any convincing examples of non-sentential assertions, there are still, in other cases of non-sentential speech, truth-conditional effects of pragmatic processes. That is, non-sentential speech can be used to call T3 into question even if there aren't any clear cases of nonsentential assertions - specifically because there are non-sentential questionings, and other speech acts. For instance, one can ask whether a demonstrated letter is from Spain by saying, with rising intonation, 'From Spain?' (And, I insist, rising intonation does not make something a sentence, either syntactically or semantically speaking. See Stainton 2000 for why.) This speech act has the illocutionary force and the truth conditions - maybe better, the satisfaction conditions - of an utterance of 'Is that from Spain?' But it does not get those satisfaction conditions merely by the assignment of reference to elements in its logical form, because what is uttered is simply a prepositional phrase. It is not an elliptical sentence and it is not "shorthand", at least not in any sense that would allow one to save T3. Thus, I believe, T3 would still not be credible, even if Stanley and Ludlow were right about T5 and T6. (Which, as I argued at length, they aren't.)

At last, let me get to the punch line about what isn't implied, and how this bears on accepting the genuineness of the phenomenon. I'm willing to grant that T3 somehow supports T1 and T2. But, I insist, it is not true that T1 and T2, either individually or together, entail T3. Nor do they entail its sub-case, T4. It is thus not necessary, to rescue $\mathrm{T} 1-\mathrm{T} 2$, that one reject pragmatic determinants of speech act content, whether assertions or other kinds. In particular, and this is crucial, T1-T2 are compatible with pragmatic determinants of speech act content in the case of sub-sentence use. That is, T1-T2 do not entail T5. ${ }^{47}$

To defend this result, I will sketch a model of linguistic communication which attracts me, and which is consistent with T1 and T2. (I do not say that all

\footnotetext{
${ }^{47}$ Jason Stanley seems to worry that one can run a long modus tollens argument, of roughly the following form:

$\mathrm{T} 1 \rightarrow \mathrm{T} 2$

$\mathrm{T} 2 \rightarrow \mathrm{T} 3$

$\mathrm{T} 3 \rightarrow \mathrm{T} 4$

$\mathrm{T} 4 \rightarrow \mathrm{T} 5$

$\neg \mathrm{T} 5$

Therefore

$\neg \mathrm{T} 1$.

Indeed, this imagined sort of argument seems to be Stanley's prime motivation for endorsing T6. But, say I, T2 (truth-conditional interpretation is different) definitely does not entail T3 (all truth-conditional effects of context come in via elements of logical form). So, the feared iterated modus tollens is, at a minimum, blocked at that point.
} 


\section{0 / Robert J. Stainton}

of the model's proponents endorse T1 and T2, especially not in this form; just that the model is consistent with them.) I will also explain along the way how that model permits one to reject T5. So, there is a way to make T1-T2 consistent with the denial of T5. Here is the idea. Following Sperber and Wilson (1986), I maintain that understanding a linguistic act involves two sorts of processes. First, there is the decoding process, a specifically linguistic process presumably carried out by a separate "language module". Decoding an expression requires knowing the language in question - knowing both its syntax and its semantics, among other things. That is why, though I can decode expressions in English, I cannot decode expressions in Japanese: I simply do not have the right knowledge base for that, stored in my "language faculty". As noted briefly in Section 1, in addition to the decoding process, I also take understanding a linguistic act to involve a general-purpose inferential process, which makes use of all available information to arrive at all-things-considered judgments. (This isn't to say that all things have been considered, of course. It rather means that all things could, in principle, end up being relevant.) In my view, this latter process is likely not confined to a special module or series of modules, precisely because it draws on information from vision and the other senses, memory, face recognition, as well as speech, and numerous other things as well. It appears, therefore, to be a nonalgorithmic process within what Fodor (1983) labels the "central system". (As should be clear, this kind of picture lends itself very naturally to the model of not-language-based informational integration, which I also take to be supported by sub-sentential speech.) That's the model of linguistic communication. On the other hand, still following Sperber and Wilson (1986), I do not believe there to be any special, task-specific, decoding process for kicks under the table, or taps on the shoulder. There is no special-purpose faculty of the mind-brain dedicated to this. Communicative acts of these sorts are understood using only the general-purpose inferential system, on the basis of commonsense knowledge. (Which is why, for instance, someone who does not speak a word of Japanese can fully understand the intent of a Japanese person who kicked them.)

Suppose the model is even broadly correct. Then $\mathrm{T} 2$ can easily be true: there would be an obvious and a fundamental difference between the two sorts of interpretation. Specifically, whereas one sort (the truth-conditional linguistic sort) involves two quite distinct processes, drawing on two quite distinct bodies of information, one of which is language-specific, the other sort (the kick/tap sort) involves a single process, and no special-purpose body of information, let alone one trained upon language. True enough, it is not the case that the 
difference between spoken communication and other sorts ends up being a matter of one single mental faculty in the truth-conditional case, and a wholly disjoint faculty in the non-linguistic case: there is, instead, some significant overlap. In particular, the second kind of "central system” process plays a part in each, because integration of the information coming from the language system happens there. But this doesn't make the difference between linguistic interpretation and non-linguistic interpretation somehow less than fundamental. (As any hapless unilingual world-traveler will tell you.)

On a Sperber and Wilson type account, then, linguistic interpretation remains fundamentally different from other kinds of communication. And that is the account I endorse. (I won't try to defend it here.) Now consider how non-sentential speech fits into this model. It quite clearly involves both of the two aforementioned processes. Returning to our first example, to understand 'Chunks of strawberries', a hearer must know (at least) the syntax and semantics of this English construction-which information is surely stored in the very same module which would allow them to understand 'Steven made jam containing chunks of strawberries'. Put otherwise, to understand 'Chunks of strawberries', used on its own, the hearer must decode this expression. Only once she has done so can general-purpose inference play its part, in determining for instance what object the speaker had in mind. Integration, then, happens separately from decoding. That non-sentential speech does in fact draw on specialpurpose knowledge of language should be absolutely evident, at least to anyone in the broadly Chomskian tradition. From the point of view of the "language module", the only difference between non-sentential speech and sentential speech, as noted above, is that the former involves the use of projections from lexical categories, of semantic type $\left.\left\langle_{e}\right\rangle,\left\langle_{e, t}\right\rangle,\left\langle<_{e, t}\right\rangle_{, t}\right\rangle$, etc., while the latter involves the use of a projection from an inflectional element, assumed to be of semantic type $<t>$. This surely is not akin to the difference between language use on the one hand, and under-the-table-kicks on the other.

In sum: $\mathrm{T} 2$ can be true in this general model of linguistic communication; and even if $\mathrm{T} 2$ is added to the general model as a hypothesis, that is not sufficient for T3 to be true as well. Moreover, the resulting bipartite picture (i.e. a twoprocess view of linguistic communication, plus a truth-centered story about type semantics) allows one to grant the genuineness of non-sentential assertion. Hence T2 doesn't entail $\neg$ T5.

I hope the foregoing at least begins to hint at why, on one reading of T1 anyway, this thesis need be no more threatened by non-sentential speech than T2 is. T1, recall, says that truth-conditional semantics is justified. True enough, 


\section{2 / Robert J. Stainton}

on one way of understanding this preservationist goal, and on one of the ways Jason Stanley intends, it is the job of semantics - read the process of compositionally determining whole-meanings on the basis of part-meanings plus structure, where part-meanings can include indexically determined denotations - to all on its own yield the truth conditions of an utterance. On this reading, T1 essentially reiterates $\mathrm{T} 3$, and hence on this reading $\mathrm{T} 1$ is in conflict with the existence of genuine non-sentential assertions. But another thing one can understand by "justifying truth-conditional semantics"— something which seems to me much more important - is justifying the idea that meaning and truth are very intimately related, an idea closely associated with Frege, Tarski, and such. If one understands T1 as saying that truth-centered semantics is justified, then nonsentential speech does not, so far as I can see, conflict with T1. For it can still be the case, at least according to one positive proposal, that linguistic expressions (types and tokens) get assigned, as extensions, things like functions from objects to truth values, or functions from such functions to truth values, etc. Indeed, on the bipartite proposal given just above - which departs from the letter of Sperber and Wilson (1986), but is consistent with the overall model of linguistic communication - truth remains absolutely central to semantics. The fact is, if one adopts my broadly pragmatic approach to the issue, while sticking to a truth-centered semantics, one might not need to make a single change to that truth-centered theory, i.e. at the level of expression types, to account for less-than-sentential speech. ${ }^{48}$ So, not only is non-sentential speech consistent with the general orientation of truth-centered semantics, it's consistent with existing detailed proposals about how truth relates to meaning.

Put another way, because of non-sentential speech, pragmatics plays a part in determining the content of what is asserted; but this doesn't mean that pragmatics plays a role in determining the reference and/or satisfaction conditions of expressions. These remain untouched. In which case, it's hard to see how non-sentential speech can pose a threat to "truth-conditional semantics" in this broad sense. In particular, non-sentential speech doesn't seem to me to raise any immediate concern for Fregean semantics, or its contemporary heirs - as long as these refrain from making claims about the determinants of speech act contents,

\footnotetext{
48 Actually, I'm not sure that every imaginable truth-centered semantic theory will be able to accommodate less-than-sentential communication this easily. For instance, a theory which said that the only things hearers have provided to them by their semantic knowledge are T-sentences might be left with an explanatory gap — since it's not clear how knowing T-sentences alone would allow one to interpret 'From Spain' or 'A healthy dollop of whipped cream'. Truth be told, however, I take this to be a good prima facie reason for not adopting such theories.
} 
and stick to describing the content of expression types. ${ }^{49}$ The same kind of lesson holds for syntax, not least because my key claims are not about the grammar itself, but about how its products can be deployed in speech acts.

Finally, let me remind you why all this matters to the issue of genuineness. T1 and T2 are very widely endorsed in philosophy and formal linguistics: a great deal of evidence would be required to make the language theory community give them up. Now suppose, contrary to what I've just argued, that T5 were entailed by T1-T2. Then there would be a very heavy burden of proof on any theorist (myself included) who argues against T5-a burden as heavy as that required on one who would deny T1 and T2 themselves. But that burden vanishes if $\mathrm{T} 1$ and $\mathrm{T} 2$ are silent on T5. Which they are. Let me also add this. If T3 and T4 aren't supported by T1-T2 - and given the availability of Sperber and Wilson's general model, there's little reason to think they are - then I can see no reason to take the former theses to be initially plausible. The default hypotheses, say. At best, one could say that T3-T4 are neutral, with the burden of proof lying equally with those who deny them and those who endorse them. If that's right, then even if T5 and T6 were true, one couldn't conclude that T3 and T4 were true. One could only conclude that the issue with respect to the latter theses remained wholly open, since they had not been proven false, but have also not been positively supported. This, I think, is the most that Stanley and Ludlow's arguments could show.

In fact, however, I have given lots of reasons for thinking that T5 and T6 are out-and-out false. These are equally reasons for thinking that there are pragmatic determinants of what is asserted, and for thinking that informational integration, even during speech comprehension, doesn't always happen via natural language. Moreover, and of most pressing concern here, they are also reasons for adopting a pragmatics-oriented approach to non-sentential speech acts.

\footnotetext{
49 Speaking of Frege, it might be thought that non-sentential speech calls into question his notorious "context principle". My own view is that there are very many ways of reading the context principle, only some of which are threatened by the existence of non-sentential speech acts. Specifically, as I explain in Stainton (2000), I ultimately do not think that non-sentential speech acts call into question Frege's key methodological idea, namely, that when asking for the meaning of some expression, one should ask how it alters truth conditions. And, given that it is this methodological principle which allows Frege to avoid psychologism — after all, what numerals contribute to truth conditions are not images or anything mental - it may be that this methodological reading is the only reading of the context principle that Frege himself should have cared about. As a result, nonsentential speech acts might pose no real problem for Frege's larger philosophy after all.
} 


\section{4 / Robert J. Stainton}

\section{REFERENCES}

Abney, Stephen (1987), 'The English Noun Phrase in its Sentential Aspect', Ph.D. diss.

(Massachusetts Institute of Technology).

Bach, Kent (1994a), 'Semantic Slack: What Is Said and More', in S. L. Tsohatzidis (ed.), Foundations of Speech Act Theory (London: Routledge), 267-91.

(1994b), 'Conversational Impliciture', Mind and Language, 9: 124-62.

Barton, Ellen (1989), 'Autonomy and Modularity in a Pragmatic Model', in B. Music,

R. Graczyk, and C. Wiltshire (eds.), Papers from the 25th Annual Regional Meeting of the Chicago Linguistic Society, Part Two: Parasession on Language in Context (Chicago: Chicago Linguistic Society), 1-14.

- (1990), Nonsentential Constituents: A Theory of Grammatical Structure and Pragmatic Interpretation (Philadelphia: John Benjamins).

_ (1998), 'The Grammar of Telegraphic Structures: Sentential and Nonsentential Derivation', Journal of English Linguistics, 26: 37-67.

— and Ljiljana Progovac (2004), 'Nonsententials in Minimalism', in Elugardo and Stainton (2004a, 71-93).

Breedin, Sarah D., and Eleanor M. Saffran (1999), 'Sentence Processing in the Face of Semantic Loss', Journal of Experimental Psychology: General, 128 4: 547-62.

Cappelen, Herman, and Ernest Lepore (1997), 'On an Alleged Connection between Indirect Quotation and Semantic Theory', Mind and Language, 12: 278-96.

Carston, Robyn (1988), 'Implicature, Explicature, and Truth-Theoretic Semantics', in R. M. Kempson (ed.), Mental Representations (Cambridge: Cambridge University Press), 155-81; repr. in Davis (1991: 33-51).

Chatterjee, Anjan, et al. (1995), 'Asyntactic Thematic Role Assignment: The Use of a

Temporal-Spatial Strategy', Brain and Language, 49: 125-39.

Chomsky, Noam (1981), Lectures on Government and Binding (Dordrecht: Foris). (1995), The Minimalist Program (Cambridge, Mass.: MIT Press).

Clapp, Lenny (2001), 'What Unarticulated Constituents Could Not Be', in J. C. Campbell, M. O'Rourke, and D. Shier (eds.), Meaning and Truth: Investigations in Philosophical Semantics (New York: Seven Bridges Press), 231-56.

Crouch, Richard (1995), 'Ellipsis and Quantification: A Substitutional Approach', Proceedings of the Seventh European Association for Computational Linguistics, 7: 229-36.

Dalrymple, Mary (2004), 'Against Reconstruction in Ellipsis', in Elugardo and Stainton (2004a, 31-55).

_ Stuart M. Shierber, and Fernando C. N. Pereira (1991), 'Ellipsis and Higher-Order Unification', Linguistics and Philosophy, 14: 399-452.

Davis, Steven (1991), Pragmatics: A Reader (Oxford: Oxford University Press).

- and Brandon Gillon (forthcoming) (eds.), Semantics: A Reader (Oxford: Oxford University Press). 
Dummett, Michael (1973), Frege: Philosophy of Language (Cambridge, Mass.: Harvard University Press).

Elugardo, Reinaldo, and Robert J. Stainton (2001), 'Logical Form and the Vernacular', Mind and Language, 16 4: 393-424.

- (2003), 'Grasping Objects and Contents', in A. Barber(ed.), The Epistemology of Language (Oxford: Oxford University Press), 257-302.

- (2004a), Ellipsis and Nonsentential Speech (Dordrecht: Kluwer).

(2004b), 'Shorthand, Syntactic Ellipsis and the Pragmatic Determinants of What Is Said', Mind and Language, 19(4): 442-71.

Fodor, Jerry A. (1983), The Modularity of Mind (Cambridge, Mass.: MIT Press).

Grice, H. Paul (1975), 'Logic and Conversation', in P. Cole and J. Morgan (eds.), Syntax and Semantics, iii: Speech Acts (New York: Academic Press), 41-58.

Hankamer, Jorge, and Ivan Sag (1976), 'Deep and Surface Anaphora', Linguistic Inquiry, 73 : 391-428.

Jarema, Gonia (1998), 'The Breakdown of Morphology in Aphasia', in B. Stemmer and H. A. Whitaker (eds.), Handbook of Neurolinguistics(San Diego: Academic Press), 221-34.

Keller, Frank, and Ash Asudeh (2001), 'Constraints on Linguistic Coreference: Structural vs. Pragmatic Factors', in Johanna D. Moore and Keith Stenning (eds.), Proceedings of the 23rd Annual Conference of the Cognitive Science Society (Mahwah, N): Lawrence Erlbaum), 483-8.

Kenyon, Tim (1999), 'Non-Sentential Assertions and the Dependence Thesis of Word Meaning', Mind and Language, 14 4: 424-40.

Kripke, Saul (1977), 'Speaker's Reference and Semantic Reference', in P. A. French, T. E. Uehling, and H. K. Wettstein (eds.), Contemporary Perspectives in the Philosophy of Language (Minneapolis: University of Minnesota Press).

Kuno, Susumu (1987), Functional Syntax (Chicago: University of Chicago Press).

Ludlow, Peter (2004), 'A Note on Alleged Cases of Nonsentential Assertion', in Elugardo and Stainton (2004a, 95-108).

Merchant, Jason (2001), The Syntax of Silence (Oxford: Oxford University Press).

Morgan, Jerry (1973), 'Sentence Fragments and the Notion "Sentence”, ' in B. Kachru et al. (eds.), Issues in Linguistics: Papers in Honor of Henry and Renee Kahane (Urbana: University of Illinois Press), 719-51.

(1989), 'Sentence Fragments Revisited', in B. Music, R. Graczyk, and C. Wiltshire (eds.), Papers from the 25th Annual Regional Meeting of the Chicago Linguistic Society, Part Two: Parasession on Language in Context (Chicago: Chicago Linguistic Society), 228-41.

Neale, Stephen (2000), 'On Being Explicit: Comments on Stanley and Szabó, and on Bach', Mind and Language, 15: 284-94.

Nespoulous, Jean-Luc, et al. (1988), 'Agrammatism in Sentence Production without Comprehension Deficits', Brain and Language, 33: 273-95.

Perry, John (1986), 'Thought without Representation', Proceedings of the Aristotelian Society, suppl. vol. 60: 137-51. 


\section{6 / Robert J. Stainton}

Pollard, Carl, and Ivan Sag (1992), 'Anaphors in English and the Scope of Binding Theory', Linguistic Inquiry, 232: 261-303.

Postal, Paul (1971), Crossover Phenomena (New York: Holt, Rinehart \& Winston).

Recanati, François (1989), 'The Pragmatics of What Is Said', Mind and Language, 4: 294-328.

Reinhart, Tanya, and Eric Reuland (1993), 'Reflexivity', Linguistic Inquiry, 24 4: 657-720.

Sag, Ivan (1976), 'Deletion and Logical Form', Ph.D. diss. (Massachusetts Institute of Technology).

- and Jorge Hankamer (1977), 'Syntactically vs. Pragmatically Controlled Anaphora', in

R. W. Fasold and R. W. Shuy (eds.), Studies in Language Variation (Washington: Georgetown University Press).

Schachter, Paul (1977), 'Does She or Doesn't She?', Linguistic Inquiry, 8: 763-7.

Searle, John R. (1978), 'Literal Meaning', Erkenntnis, 13: 207-24.

— (1980), 'The Background of Meaning', in J. Searle, F. Kiefer, and M. Bierwisch (eds.), Speech Act Theory and Pragmatics (Dordrecht: Reidel), 221-32.

Sellars, Wilfrid (1954), 'Presupposing', Philosophical Review, 63: 197-215.

Sirigu, Angela (1998), 'Distinct Frontal Regions for Processing Sentence Syntax and Story Grammar', Cortex, 34: 771-8.

Sperber, Dan, and Deirdre Wilson (1986), Relevance (Cambridge, Mass.: Harvard University Press).

Sportiche, Dominique (1988), 'A Theory of Floating Quantifiers and its Corollaries for Constituent Structure', Linguistic Inquiry, 193: 425-49.

Stainton, Robert J. (1993), 'Non-Sentential Assertions', Ph.D. diss. (Massachusetts Institute of Technology).

(1994), 'Using Non-Sentences: An Application of Relevance Theory', Pragmatics and Cognition, 22: 269-84.

(1995), 'Non-Sentential Assertions and Semantic Ellipsis', Linguistics and Philosophy, 18 3: 281-96.

- (1997a), 'What Assertion Is Not', Philosophical Studies, 85 1: 57-73.

(1997b). 'Utterance Meaning and Syntactic Ellipsis', Pragmatics and Cognition, 51: 49-76.

(1998a), 'Quantifier Phrases, Meaningfulness “in Isolation”, and Ellipsis', Linguistics and Philosophy, 21: 311-40; repr. in Davis and Gillon (forthcoming).

(1998b), 'Unembedded Definite Descriptions and Relevance', Revista Alicantina de

Estudios Ingleses, special issue: Relevance Theory, 11:231-9.

(2000), 'The Meaning of "Sentences” ', Nous, 34 3: 441-54.

(2004), 'The Pragmatics of Non-Sentences', in L. Horn and G. Ward (eds.), The

Handbook of Pragmatics (Oxford: Basil Blackwell), 266-87.

— and Alisa Hillier (1990) (eds.), A Le Camp Sourcebook (Toronto: Applied Linguistics Research Working Group, Glendon College of York University).

Stanley, Jason (2000), 'Context and Logical Form', Linguistics and Philosophy, 23 4: 391-434.

- and Zoltán G. Szabó (2000), 'On Quantifier Domain Restriction', Mind and Language,

15: 219-61. 
Tanenhaus, Michael K., and Greg N. Carlson (1990), 'Comprehension of Deep and Surface Verb Phrase Anaphors', Language and Cognitive Processes, 5 4: 257-80.

Travis, Charles (1985), 'On What is Strictly Speaking True', Canadian Journal of Philosophy, 152: $187-229$.

— (1996), 'Meaning's Role in Truth', Mind, 100: 451-66.

_ (1997), 'Pragmatics', in B. Hale and C. Wright (eds.), A Companion to the Philosophy of Language (Oxford: Basil Blackwell), 87-107.

Varley, Rosemary (1998), 'Aphasic Language, Aphasic Thought: An Investigation of Propositional Thinking in A-Propositional Aphasic', in P. Carruthers and J. Boucher (eds.), Language and Thought: Interdisciplinary Themes (Cambridge: Cambridge University Press), 128-45.

Williams, Edwin (1977), 'Discourse and Logical Form', Linguistic Inquiry, 8 1: 101-39.

Wilson, Peter (2000), Mind the Gap (Harlow: Pearson Education).

Yanofsky, Nancy (1978), 'NP Utterances', in D. Farkas, W. Jacobsen, and K. Todrys (eds.), Papers from the Fourteenth Regional Meeting: Chicago Linguistics Society (Chicago: Chicago Linguistics Society), 491-502.

Zribi-Hertz, Anne (1989), 'Anaphor Binding and Narrative Point of View: English Reflexive Pronouns in Sentence and Discourse', Language, 65: 695-727. 
